\title{
Transportation Costs, Agricultural Productivity and Cross-Country Income Differences*
}

\author{
Tasso Adamopoulos ${ }^{\dagger}$ \\ York University
}

This Draft: November 2005

\begin{abstract}
There are large differences in transportation infrastructure across nations. Constructing a measure of transportation infrastructure density for a large set of countries, I show that the disparity in this measure between the $5 \%$ income rich and the $5 \%$ income poor countries is a factor of 28 . Are these differences a source of productivity differences across nations? Using a three-sector, two-region, general equilibrium model, I show that high transport costs can distort the allocation of resources not only across geographically dispersed production units within sectors but also between agriculture and non-agriculture. Taking as given the observed differences in transportation infrastructure densities, I quantify the role of transportation for cross-country income differences. The calibrated model produces an income disparity of 10.9 between the $5 \%$ rich and $5 \%$ poor countries. This corresponds to an improvement of $35 \%$ relative to the disparity predicted by a two sector model of agriculture and non-agriculture. Furthermore, the effects of advancements in transportation are non-linear: the elasticity of aggregate labor productivity with respect to the stock of transportation infrastructure in the poorest nations is 15 times higher than in the richest ones.
\end{abstract}

JEL classification: O1, O4, Q10.

Keywords: Productivity Comparisons, Agriculture, Transportation Costs.

\footnotetext{
*I am grateful to Ahmet Akyol, Michelle Alexopoulos, Gueorgeui Kambourov, Angelo Melino, Diego Restuccia, Richard Rogerson, Shouyong Shi and Xiaodong Zhu for their many helpful comments and suggestions. All errors are my own.

${ }^{\dagger}$ Department of Economics, York University, Vari Hall 1036, 4700 Keele Street, Toronto, Ontario M3J 1P3, Canada. Tel.: +1-416-736-2100 (ext.33269); fax: +1-416-736-5987. Email: tasso@econ.yorku.ca.
} 


\section{Introduction}

There are large differences in transportation infrastructure and technology across countries and these differences are systematically correlated with the level of development. For example, the 5 richest countries of the world have $24.5 \mathrm{~km}$ of total road and $1.8 \mathrm{~km}$ of railroad for every 1000 people while the 5 poorest have $1.5 \mathrm{~km}$ of total road and $0.05 \mathrm{~km}$ of railroad for every 1000 people (factor differences of 14 and 30 respectively). Furthermore, there are large differences in the efficiency and quality of these networks. In the 5 richest countries $61 \%$ of the total road network is paved while in the 5 poorest only $16 \%$ is paved. Out of the paved road network in the poor countries $33 \%$ is in fair condition while $20 \%$ is in poor condition. ${ }^{1}$

In this paper, I ask whether these large disparities in countries' transporting abilities are a significant source of aggregate labor productivity differences. I argue they are. First, I consider how transportation total factor productivity (TFP) can impact aggregate income, from a theoretical point of view. Second, using an internationally comparable measure of transportation infrastructure density, as a proxy for a country's transport TFP, I ask how much of the current cross-country income differences can the observed differences in transportation TFP account for.

At the qualitative level, I show that low transportation TFP can lead to low aggregate output per worker, not only by reducing the average level of productivity within each industry but also by altering the mix of economic activity between agriculture and non-agriculture. The focus on the agricultural versus non-agricultural division of output is motivated by the striking evidence that poor countries are not only particularly unproductive in agriculture relative to rich countries, but they also devote an inordinate amount of resources to that activity. $^{2}$ Understanding why developing countries are so unproductive in agriculture, and yet devote so many resources to it, can be essential for understanding why they have such low income. As Schultz put it in his Nobel Prize Lecture, "Most of the world's poor people earn their living from agriculture, so if we knew the economics of agriculture, we would know

\footnotetext{
${ }^{1}$ Details on the data sources are provided in Section 2 and Appendix A.

${ }^{2}$ Agricultural productivity differences are starker than the aggregate productivity differences: the 5 richest countries are 32 times more productive than the 5 poorest at the aggregate level but 71 times more productive in agriculture. Furthermore, the share of labor employed in agriculture is also systematically related to the level of development: the poorest countries devote as much as $90 \%$ of their labor to agriculture while the richest as low as 5\%. See Section 2 of this paper as well as Restuccia, Yang and Zhu (2004).
} 
much of the economics of being poor." 3

In this paper, I argue that a low TFP in transportation increases the cost of transporting final goods and intermediate inputs used in farming - these inputs include chemical fertilizers, pesticides, processed seeds, fuel, energy - across regions. Higher freight costs operate as natural barriers that distort the efficient spatial distribution of production because they prevent regions from specializing in the goods in which they possess a comparative advantage. The misallocation of resources across heterogeneous (with respect to their productivity) production units within sectors reduces average productivity at the industry level. Higher freight costs have an additional adverse impact on agricultural productivity because they reduce farmers' access to the technology embodied in the modern intermediate inputs.

Lower industry productivity is of particular importance in the case of agriculture, given that many developing countries are close to subsistence consumption, and suffer from what Schultz (1953) called the "food problem": because of their low productivity in farming, they have to devote even more resources to that activity to meet the subsistence levels of the population's consumption. I show that, within a country, the negative relationship between agricultural productivity and the share of labor in farming need not hold if one region of the country is more productive than another, and the two regions can trade. The region with the low productivity can import food from the region with the high productivity thereby circumventing its inefficiency in farming. Low TFP in transportation, by rendering such trades unprofitable, forces individuals in the less productive regions to devote even more time to farming to meet their subsistence food requirements, raising the overall weight of agriculture in economic activity.

I illustrate the role of transportation costs on the level and the composition of GDP, using a multi-sector general equilibrium model of cross-regional trade. To focus on within country transportation TFP, I treat each country as a closed economy, consisting of two regions. One region has a comparative advantage in agriculture and the other in non-agriculture. The interaction of two constraints is key for the main results of the paper. First, cross-regional trade requires transportation services, produced in the economy's transport sector. Second, there are subsistence food requirements of the population. Poor infrastructure lowers the

\footnotetext{
${ }^{3}$ Theodore W. Schultz, "The Economics of Being Poor", Nobel Prize Lecture, December 81979.
} 
average productivities in agriculture and in non-agriculture but has a larger impact on the former because of the subsistence constraint in food consumption.

Qualitatively, the model can account for the following observations for developing countries: (1) the low productivity in agriculture, (2) the high proportion of labor in farming, (3) the low use of intermediate inputs in farming by the agricultural producing regions, (4) the low aggregate productivity.

In my quantitative work, I use internationally comparable, aggregate data from the Penn World Tables (PWT), agricultural data from the Food and Agricultural Organization (FAO) of the United Nations, and transportation infrastructure data from the World Bank. I measure economy-wide productivity differences across countries by using GDP per worker in nonagriculture. I also measure land to population ratios as arable land per person in each country. Finally, I measure transportation TFP as transportation infrastructure per person. The first question I ask is: how much of the cross-country differences in aggregate labor productivity, agricultural labor productivity, employment shares, intermediate input use in farming, can the model account for, for exogenous differences in economy-wide productivity, land to population ratios, and transportation TFP? The model produces an income disparity of 10.9 between the $5 \%$ richest and $5 \%$ poorest nations. This number is $35 \%$ higher than the one predicted by a two-sector model of agriculture and non-agriculture with the same exogenous economy-wide productivity differences and land to population ratios. The results imply that the transportation system can be an important source of low income in poor countries.

I also use the model to conduct policy experiments on the quantitative impact of transportation improvements in developed and developing countries. The experiments illustrate that the effects of changes in transportation TFP are non-linear: poor countries are more likely to benefit from an improvement in transportation TFP than rich countries. I find that the elasticity of aggregate real GDP per worker with respect to transportation TFP differs between the $5 \%$ poor and the $5 \%$ rich countries by a factor of 15 . The factor difference for the elasticity of agricultural real GDP per worker is 10.6. The intuition behind these results is that rich countries already have well functioning transport networks and therefore have exploited most of the cross-regional potential gains from trade. Poor countries, because of their poor infrastructure have large unexploited gains from trade, and therefore, will benefit 
substantially from marginal improvements in transportation. From a policy perspective, this implies that a dollar spent on transportation infrastructure in a developing country will go a long way compared to a developed country.

I provide a specific example on the potential quantitative gains from transportation improvements, for developing nations. I use state-level data on agriculture from India, to calculate labor productivities for its major regions. Using my model, I show that given the current distribution of agricultural productivities across states, India can realize an increase in its agricultural and aggregate labor productivity, of $11 \%$ and $7 \%$ respectively, by doubling its transportation infrastructure.

This paper is closely related to the macroeconomics literature that tries to understand quantitatively the sources of aggregate labor productivity differences across nations: for example, Mankiw, Romer and Weil (1992), Chari, Kehoe, and McGrattan (1996), McGrattan and Schmitz (1998). A large branch of the quantitative literature has focused on quantifying the contributions of factors vs. TFP to cross-country income differences, using an aggregate production function. The current consensus is that TFP is the main proximate cause of labor productivity differences across countries (Klenow and Rodriguez-Clare 1997; Hall and Jones, 1999; Prescott, 1998; Parente and Prescott, 2000). There are two key follow-up questions. (1) What are the sources of differences in TFP?, (2) How do differences in TFP differ across different economic activities? Acquiring a better description of the nature of TFP differences (second question) can be useful in developing theories of TFP (first question). The above literature has abstracted from differences in the sectoral composition of output across countries. In this paper, I show that sectoral productivity differences are important for understanding aggregate income differences. I emphasize TFP in transportation, not only as a direct source of income differences across nations, but primarily as a source of differences in the productivity of the rest of the economy.

There is a growing literature that uses variants of the two sector growth model with agriculture and non-agriculture, to understand income differences across countries: Gollin, Parente and Rogerson (2002, 2004), Caselli (2004), Restuccia, Yang and Zhu (2004), Cordoba and Ripoll (2005), among others. There are two implicit motivations behind this approach. First, the process of development is accompanied by a process of structural transformation, 
namely the movement of resources out of agriculture and into industry and services. ${ }^{4}$ Second, as emphasized earlier, today poor countries still have most of their labor force in farming. A common insight of this literature is that low agricultural productivity is important in understanding and interpreting the current situation of poor countries.

The present paper complements the literature on two-sector models. A common assumption in this literature, is that agricultural output is produced in a single country-wide farm and manufacturing output is produced in a single country-wide factory. Here, I make the point that output is produced by different units which are spatially dispersed and which may enjoy different production opportunities. I show that the extent of trade between regions with different sectoral production functions relies heavily on the existence of a well functioning transportation network. The novelty of my approach is the emphasis on transportation inefficiencies as a channel that endogenously leads to low agricultural productivity and high labor share in farming.

The paper is also closely related to Restuccia and Rogerson (2003), which studies, in a growth model with heterogeneous plants, how idiosyncratic price distortions can reduce output by misallocating resources across establishments that differ in their productivity levels. The present paper can be thought of as putting structure on transportation costs as one possible source of the heterogeneity in prices faced by individual producers within countries.

There is an extensive empirical literature in economic growth and development that studies the effect of infrastructure on aggregate income and agricultural productivity. For example, Easterly and Rebelo (1993) find that public investment in transportation and communication is positively correlated with economic growth. The literature that has examined the impact of infrastructure on agriculture finds that improved road quality increases the use of fertilizer (Ahmed and Hossain, 1990), enhances agricultural output with an elasticity of about 0.20 (Binswanger, Khandaker and Rosenzweig, 1993), and raises agricultural productivity in developing countries (Antle, 1983; Craig, Pardey, and Roseboom, 1997).

Poor transportation infrastructure can have large effects on intra-national transportation

\footnotetext{
${ }^{4}$ Development economists have long described the process of the structural transformation: Schultz (1953), Fei and Ranis (1964), Kuznets (1966), Chenery and Syrquin (1975). A more recent literature formalizes this process using multi-sector general equilibrium models: Echevarria (1997), Kongsamut, Rebelo, and Xie (2001), Lucas (2000), Caselli and Coleman (2001), Hansen and Prescott (2002), Ngai and Pissarides (2005).
} 
costs. Minten and Kyle (1999), in a case study of food trade in former Zaire, find that due to the poor condition of rural roads transport costs make up one-quarter to one-third of the wholesale price of domestic products. They also find that transportation is on average two times more expensive on bad roads than on paved roads. Limao and Venables (2001) find that poor infrastructure accounts for $40 \%$ of predicted transport costs for coastal economies and $60 \%$ for landlocked economies.

Economic historians, such as North (1958), have argued that the reduction in transportation costs in the 19th century was a major factor in the growth of the United States and Europe. Rostow (1956) has claimed that "the introduction of the railroad has been historically the most powerful single initiator of take-offs". There is a rich literature that has studied the transportation revolution and its significant effects on U.S. economic growth: for example, Taylor (1964), Fishlow (1965, 2000), Williamson (1974), Schmitz (2003). ${ }^{5}$ In light of the importance of historical transportation improvements for today's developed countries, it seems natural to ask: how would today's poor countries, many of which do not have transport networks equivalent to those of 19th century U.S., benefit from improvements in their transportation systems?

The papers most closely related to this one are Restuccia, Yang and Zhu (2004), and Schmitz (2003). The use of intermediate inputs and the presence of economy-wide productivity in agriculture are similar to Restuccia, Yang, and Zhu (2004), who also study international differences in agricultural and aggregate productivity. The key difference between my paper and their's is that I focus on regional trade and transportation as the source of such productivity differences. Schmitz (2003) similarly models regional trade, but the structure of preferences and production technologies is different. Furthermore, Schmitz (2003) studies the effect of transportation on U.S. growth historically, while I study income differences in a cross-section of countries.

The rest of the paper is organized as follows. Section 2 presents some empirical observations. Section 3 presents the model used in the quantitative exercises and describes a simple

\footnotetext{
${ }^{5}$ Fogel (1964) challenged the view that the railroads were "indispensable" for U.S. economic development, and calculated that the GNP loss wouldn't have been more than 5\%. Fogel however, asked a very specific question: what would have GNP been in 1890 if the railroad had not been adopted. Holmes and Schmitz (2001) argue that after relaxing some of Fogel's assumptions the number can be much larger, even for the question Fogel asked.
} 
analytical case. Section 4 contains the quantitative experiments and Section 5 contains the concluding remarks.

\section{Some Observations}

Assessing quantitatively the effect of the transportation sector on the level and composition of aggregate labor productivity requires internationally comparable aggregate and industry productivity data and a measure of a country's transporting ability.

I use aggregate productivity and aggregate price data from the Penn World Tables (PWT5.6) and agricultural productivity and agricultural price data from the Food and Agricultural Organization (FAO) of the United Nations. To quantify a country's transporting ability I construct a measure of transportation infrastructure using data from the World Bank's infrastructure data base. The years and countries covered in these data sets differ. For maximum country coverage I use 1985 data for a cross-section of 86 countries. A more detailed description of the data is provided in Appendix A.

The FAO productivity data, reported in Rao (1993), are the natural data to use for crosscountry agricultural sector comparisons because, (i) they are PPP adjusted (in a way similar to the PWT data), and (ii) they are valued at producer prices, that is prices received/paid by farmers at the farm gate (contrary to the PWT which are valued at retail prices). ${ }^{6}$

Table A.1 in Appendix A, contains summary statistics on aggregate GDP per worker, agricultural GDP per worker, agricultural final output per worker, non-agricultural GDP per worker, the employment share in agriculture, and the intermediate input intensity. ${ }^{7}$ In particular, I report for each variable, the average of the rich $5 \%$ and the poor $5 \%$ (ranked according to GDP per worker), as well as their ratio. There are several striking observations, which have been previously documented elsewhere. ${ }^{8}$ First, aggregate labor productivity in the

\footnotetext{
${ }^{6}$ In fact, failure to use producer prices can lead to misguided inferences about cross-country industry productivity differences. For example, according to the U.S. Department of Agriculture out of every dollar spent on food in the U.S., 80 cents is marketing and distribution charges, and only 20 cents is producer cost.

${ }^{7}$ Agricultural GDP is calculated as agricultural final output, less the value of intermediate inputs used in agriculture. The intermediate input intensity is calculated as the ratio of the value of intermediate inputs over the value of final agricultural output.
}

${ }^{8}$ See for example Restuccia, Yang, and Zhu (2004). 
5 richest countries of the world is 32 times higher than in the 5 poorest. Second, agricultural GDP per worker in the 5 richest countries in the world is 71 times higher than in the 5 poorest. Third, the poorest countries allocate $90 \%$ of their labor force to agricultural production while the richest only 5\%. From a quantitative standpoint alone, these observations suggest that poor countries are poor because they have a very large weight on the sector in which they are particularly unproductive: agriculture.

The statistics for the measure of transportation ability, which I construct here, are reported in the last column of Table A.1. I use differences in transportation infrastructure stocks to proxy for differences in countries' abilities to transport final and intermediate goods. Canning (1998) has compiled a data set for the World Bank on transportation and communications infrastructure, for a large set of countries and for a large number of years. I use data from Canning (1998) on (1) $\mathrm{km}$ of total road, (2) $\mathrm{km}$ of paved road, and (3) $\mathrm{km}$ of railroad to construct a transportation infrastructure index. For each country I express the three measures in per 1000 persons of its population to account for differences in size. Then, I normalize each density variable so that it has a mean of one. The index is simply a linear combination of the three normalized density variables, which is equivalent to assuming that roads, paved roads and railways are perfect substitutes as inputs to a transport services production function. ${ }^{9}$

The transportation infrastructure index between the 5 richest and the 5 poorest countries in 1985 differs by a factor of 28, a factor difference almost as large as the aggregate income disparity. Furthermore, the index is systematically related with the level of development. As Fig.1 - Fig.6 and Table A.2 in Appendix A indicate, the transportation index is positively correlated with real GDP per worker, agricultural real GDP per worker, non-agricultural real GDP per worker, the proportion of intermediate inputs used in agricultural output, and negatively correlated with the share of labor employed in agriculture and the relative price of intermediate inputs used in agriculture. Fig.1 - Fig.6 include scatterplots of each of the above variables against the transportation infrastructure index and the fitted values from a

\footnotetext{
${ }^{9}$ Qualitative results are similar if instead I normalize $\mathrm{km}$ of roads, paved roads and rails by total land area (sq $\mathrm{km}$ ) or arable land area (hectares). However, normalizing the variables by the population is preferable because the land measures make countries like the US, Canada, Australia appear to have a low density measure, due to their large surface.
} 
linear regression of each variable on the index (solid line in each graph). ${ }^{10}$

Fig.1 - Fig.6 and Table A.2 display simple pair-wise correlations and are not intended to provide hard evidence on the existence of a causal effect of transportation infrastructure on productivity and other key variables, or as evidence on the magnitude of such an effect. The reason is that there are many factors for which productivities differ across countries, which are not taken into account above. To determine the effect of transportation infrastructure on productivity, analysis requires that other factors are controlled for. In the next section I do this following a structural approach by specifying a general equilibrium model that controls for preference and technology features and quantitatively isolates the effect of the transportation sector on productivity.

Even though the differences in the transportation infrastructure index between developed and developing countries are very large, they are likely to underestimate the true differences in the ability of countries to transport goods. The reason is that the index above captures only stocks and does not provide information on the quality or efficiency of the transportation network within a country. Canning (1998) has compiled data for some countries, which indicate the proportion of the total and the paved network that are in poor and fair condition. From the countries for which data is available in 1984, the 5 poorest countries had $33 \%$ of main paved roads in fair condition and $19 \%$ in poor condition. For main unpaved roads these numbers were $34 \%$ and $38 \%$ respectively.

Other transportation infrastructure data, such as the number of lanes, the presence of an important bridge or canal, are not contained in the transportation index. ${ }^{11}$ Government transportation policies, network management, and the efficiency of transportation technologies are not present either. One would expect these to be systematically correlated with the level of development, in which case they would only exacerbate the differences presented above. It could be argued that the relative cost of transporting goods or the transportation margin in retail prices would reflect all the possible differences in the efficiency of transporta-

\footnotetext{
${ }^{10}$ The figures suggest that the relationships between the key variables and the transportation infrastructure index are actually non-linear. Given that the focus of the paper is the spread between the richest and poorest nations, I do not emphasize this non-linearity.

${ }^{11}$ A country's transporting ability is also heavily affected by the geographical morphology of the country, e.g., whether there are rivers and other natural waterways or whether the country is mountainous. Lack of a comprehensive database with this information does not permit to include these indicators of transporting ability in the measure I use.
} 
tion systems across countries. The problem with such measures (besides that they are not available for a large set of countries) is that when these costs are so prohibitively high that the trade doesn't take place they are not recorded. The above index, even though it gives an incomplete picture of reality, is not subject to such caveats.

An implicit assumption in my argument is that there are agricultural productivity differences across regions within countries. Indeed, there are large differences in inherent land quality not only across countries but also across regions within countries. This is revealed by Map 1, constructed by the FAO and the International Institute for Applied Systems Analysis (IIASA), which ranks global land with respect to its suitability for agricultural production. This characterization is based on utilizing data on soil, terrain and climate characteristics. From this map it is clear that not all regions within countries are suitable for agriculture.

Global agricultural land cover data however, reveal that many regions world-wide which are constrained or unsuitable for agriculture still engage in farming. For example, Map 2 generated from satellite imagery with a resolution of one kilometer from the U.S. Geological Survey, shows the current global land cover, including agricultural lands such as cropland. From this map it seems that developed countries like the U.S. have a spatial distribution of farming activities that is more consistent with the inherent fertility of their land. According to the Economic Research Service of the U.S. Department of Agriculture (USDA), among the Sub-Saharan African countries an average of only $6 \%$ of the cropland had soils and climates well-suited for agricultural production. One possible reason for the mismatch between land quality and farming and the consequent low agricultural productivity in poor countries could be the lack of a well established transportation system. In the next section, I develop a general equilibrium model to explore this qualification.

\section{A Model of Cross-Regional Transportation}

First, I put forth the environment of the model and derive the main equilibrium conditions. Then, I solve for the system of non-linear equations, which I will use in the quantitative experiments. Finally, I present a simple version of the model analytically. 


\subsection{Environment}

Consider a single country with two regions, East $(E)$ and West $(W)$. Each region $j \in\{E, W\}$ can produce two tradable goods, an agricultural good $(a)$ and a manufacturing good $(m){ }^{12}$ The manufacturing good can be produced according to a technology that exhibits constant returns to scale,

$$
Y_{m j}=A \varepsilon_{m j} n_{m j}^{\sigma} L_{m j}^{1-\sigma}
$$

where $Y_{m j}$ is output, $n_{m j}$ and $L_{m j}$ are the labor and land inputs in the manufacturing sector of region $j \in\{E, W\} . \sigma<1$ is the labor elasticity parameter of the manufacturing technology. $\varepsilon_{m j}$ is a technology parameter, specific to manufacturing in region $j$. $A$ is an economy-wide TFP parameter, common to both sectors and both regions. $A$ is meant to capture all those factors, such as restrictions on technology, institutions, and policies, that affect all industries and all regions within a country.

In each region the agricultural good can be produced using a constant returns to scale technology, 13

$$
Y_{a j}=\left[\left(A \varepsilon_{a j} n_{a j}\right)^{\alpha} L_{a j}^{1-\alpha}\right]^{\beta} z_{a j}^{1-\beta}
$$

where $z_{a j}$ is the intermediate input used in farming, which is produced in the $m$ sector. $Y_{a j}$, $n_{a j}, L_{a j}$ are output, labor input and land input in the agricultural sector. The parameters $\alpha$ and $\beta$ take values in $(0,1) . \varepsilon_{a j}$ is a technological parameter, specific to agriculture in region $j$. The motivation for including intermediate inputs in the farming technology is the observation that the use of intermediate inputs in agriculture is systematically correlated with the level of development and the transportation infrastructure density (see Section 2).

I assume that the West has a comparative advantage in producing the agricultural good and therefore if trade takes place the East will export the manufacturing good and will import the agricultural $\operatorname{good}^{14}$.

Trade between regions requires transportation services which are produced in the region of the exporter (transport costs are incurred once per trade) according to the following tech-

\footnotetext{
${ }^{12}$ In the quantitative section, the manufacturing sector will include all other activities besides agriculture and transportation, and will be measured as the non-agricultural sector.

${ }^{13}$ For an empirical justification of the Cobb-Douglas technology forms see Hayami and Ruttan (1985).

${ }^{14}$ Proposition 1 describes the condition that gives rise to this pattern of trade.
} 
nologies, for $j \in\{E, W\}$,

$$
Y_{t j}=A_{t} n_{t j}
$$

where $Y_{t j}, n_{t j}$ are output and labor input in the transportation sector of region $j$. Notice that transportation TFP, $A_{t}$, is the same for both regions, capturing the idea that if a transportation network is in place, then it can be used as efficiently by both regions. This parameter can represent infrastructure capital, the structure of the transportation sector, inefficiencies in coordination, or government transportation policies. ${ }^{15}$ In the quantitative work however it will be proxied by the transportation infrastructure index discussed in Section 2.

Transportation services are required for transporting both, intermediate inputs and final consumption goods. The export technologies of the two regions are assumed to be Leontief, ${ }^{16}$

$$
\begin{gathered}
M_{a E}=\varphi_{a} \min \left\{X_{a W}, t_{a W}\right\} \\
M_{m W}=\varphi_{m} \min \left\{X_{m E}, t_{m E}\right\}
\end{gathered}
$$

where $\varphi_{i}<1$ is the fraction of each shipped unit of good $i$ that arrives to its destination, and can be thought of as an iceberg cost. $M_{a E}$ are the imports of agricultural goods in the East, $X_{a W}$ are the exports of agricultural goods from the West, and $t_{a W}$ are the transportation services required to deliver the agricultural goods from the West to the East. The second equation has a similar interpretation, with the difference that exports and imports include not only the final manufactured consumption goods but also the intermediate inputs. Note

\footnotetext{
${ }^{15}$ In this static model without capital, the TFP parameters will include capital as well. There are a number of reasons for following this approach. First, sectoral capital stock data are not available for the large range of countries included in the quantitative analysis. Second, I do not want to take a stance on whether sectoral productivity differences across countries are transitional or steady-state. Third, the debate on capital accumulation vs. TFP suggests that TFP differences are the main source of cross-country income differences. For transportation in particular, a large part of the infrastructure is government provided. A careful treatment of capital in transportation would have to account for the distinction between private and public capital. Here, I abstract from these issues and include them all under transport TFP.

${ }^{16}$ The Leontief nature of the export technologies implies that for every unit of physical good traded, one unit of transportation services is needed. This implies that when transport TFP is low many resources are required to deliver given amounts of goods, but as transport TFP improves resources are released to the production of goods. This implication is consistent with the time series data for the United States, which suggest that since the 19th century, the share of labor employed in transportation declined. See for example Glaeser and Kohlhase (2003).
} 
that in this model, the relative price of intermediate inputs to final manufactured goods is one, within each region.

Labor is mobile across sectors within regions but immobile across regions. Let $n_{j}$ be the total population endowment of region $j$. The land endowments are region and sector specific. Notice that, the fixity of the supply of land for each technology implies that the labor input exhibits decreasing returns under each technology.

Preferences over the agricultural and the non-agricultural goods are the same across regions. In particular, consumers in each region have non-homothetic preferences with a subsistence requirement for food, ${ }^{17}$

$$
\max \left\{\phi \ln \left(c_{a j}-\bar{a}\right)+(1-\phi) \ln \left(c_{m j}\right)\right\}
$$

s.t.

$$
p_{a j} c_{a j}+p_{m j} c_{m j}=y_{j}
$$

where $y_{j}=\frac{1}{n_{j}}\left\{w_{j} n_{j}+\pi_{a j} L_{a j}+\pi_{m j} L_{m j}\right\}$ is per capita income in region $j . c_{a j}$ and $c_{m j}$ are per capita consumption of the farmed and the manufactured good. $\bar{a}$ is subsistence consumption of food. $\phi \in(0,1)$ is the weight of food in the consumer's utility function. $p_{a j}$ and $p_{m j}$ are the prices of the final consumption goods paid by consumers, which include transportation charges.

\subsection{Equilibrium Conditions}

The first order conditions for the profit maximization problem of the agricultural firm in region $j \in\{E, W\}$ are,

$$
\begin{gathered}
\alpha \beta p_{a j}\left(\varepsilon_{a j} A\right)^{\alpha \beta} n_{a j}^{\alpha \beta-1} L_{a j}^{(1-\alpha) \beta} z_{a j}^{1-\beta} \leq w_{j} ; n_{a j} \geq 0 \\
(1-\alpha) \beta p_{a j}\left(\varepsilon_{a j} A\right)^{\alpha \beta} n_{a j}^{\alpha \beta} L_{a j}^{(1-\alpha) \beta-1} z_{a j}^{1-\beta} \leq \pi_{a j} ; L_{a j} \geq 0 \\
(1-\beta) p_{a j}\left(\varepsilon_{a j} A\right)^{\alpha \beta} n_{a j}^{\alpha \beta} L_{a j}^{(1-\alpha) \beta} z_{a j}^{-\beta} \leq p_{m j} ; z_{a j} \geq 0
\end{gathered}
$$

\footnotetext{
${ }^{17}$ For empirical support on subsistence food requirements, see Rosenzweig and Wolpin (1993), as well as Atkenson and Ogaki (1996).
} 
all with complementary slackness. $w_{j}$ is the rental price of labor in region $j$, common to all sectors. $\pi_{a j}$ are the profits accruing to the farm in region $j . p_{m j}$ is the price of the intermediate input produced in the $m$ sector which is the same as the price of the consumption good produced in that sector.

The first order conditions of the maximization problems in the manufacturing and transportation sectors are,

$$
\begin{gathered}
p_{m j} \sigma A \varepsilon_{m j} n_{m j}^{\sigma-1} L_{m j}^{1-\sigma} \leq w_{j} ; n_{m j} \geq 0 \\
p_{m j}(1-\sigma) A \varepsilon_{m j} n_{m j}^{\sigma} L_{m j}^{-\sigma} \leq \pi_{m j} ; L_{m j} \geq 0 \\
p_{t j} A_{t j} \leq w_{j} ; n_{t j} \geq 0
\end{gathered}
$$

with complementary slackness. $p_{t j}$ is the price of one unit of transportation services, and $\pi_{m j}$ are the profits of the manufacturing firm.

If trade occurs between the two regions, the West will export the agricultural good to the East and will import the manufacturing consumption good and the intermediate input from the East. Given the form of the export technologies, optimality requires that,

$$
\begin{gathered}
\frac{M_{a E}}{\varphi_{a}}=X_{a W}=t_{a W} \\
\frac{M_{m W}}{\varphi_{m}}=X_{m E}=t_{m E}
\end{gathered}
$$

The first order condition for the exporters imply the following pricing functions,

$$
\begin{gathered}
p_{a E}=\frac{1}{\varphi_{a}}\left[p_{a W}+p_{t W}\right] \\
p_{m W}=\frac{1}{\varphi_{m}}\left[p_{m E}+p_{t E}\right]
\end{gathered}
$$

The first order conditions to the household's problem in region $j \in\{E, W\}$ are,

$$
\begin{gathered}
c_{a j}=\bar{a}+\frac{\phi}{p_{a j}}\left(y_{j}-\bar{a} \cdot p_{a j}\right) \\
c_{m j}=\frac{1-\phi}{p_{m j}}\left(y_{j}-\bar{a} \cdot p_{a j}\right)
\end{gathered}
$$


According to (13)-(14), once the subsistence needs of the population have been met, the rest of the income is proportionately allocated between the two consumption goods.

There are a number of potential trade equilibria in the model depending on the parameter values. The focus here is on a trade equilibrium with incomplete specialization, in which both regions produce both goods, but the West also exports the agricultural good and the East exports the manufactured good. ${ }^{18}$ In this type of equilibrium, the market clearing conditions in the West are,

$$
\begin{gathered}
n_{a W}+n_{m W}+n_{t W}=n_{W} \\
t_{a W}=Y_{t W} \\
c_{a W} \cdot n_{W}+X_{a W}=Y_{a W} \\
c_{m W} \cdot n_{W}+z_{a W}=Y_{m W}+M_{m W}
\end{gathered}
$$

The market clearing conditions in the East are,

$$
\begin{gathered}
n_{a E}+n_{m E}+n_{t E}=n_{E} \\
t_{m E}=Y_{t E} \\
c_{a E} \cdot n_{E}=Y_{a E}+M_{a E} \\
c_{m E} \cdot n_{E}+z_{a E}+X_{m E}=Y_{m E}
\end{gathered}
$$

\subsection{Autarkic Equilibrium}

Before I analyze the trade equilibrium, it is instructive to consider the scenario in which the two regions behave as two autarkic economies. Under autarky, the market clearing conditions for each region $j$ are,

$$
c_{a j} \cdot n_{j}=Y_{a j}
$$

\footnotetext{
${ }^{18}$ In the presence of decreasing returns in the production of the two goods, both regions must produce both goods. A trade equilibrium in which one region doesn't produce one good requires that for that region the marginal cost of producing it is higher than the marginal value product of labor. But decreasing returns do not permit this, because as the labor share approaches zero the marginal product of labor in that sector goes to infinity.
} 


$$
\begin{gathered}
c_{m j} \cdot n_{j}+z_{a j}=Y_{m j} \\
n_{a j}+n_{m j}=n_{j}
\end{gathered}
$$

Definition 1. An autarkic equilibrium for each region $j$ is a set of local commodity prices $\left\{p_{a j}, p_{m j}\right\}$, a set of local factor returns $\left\{w_{j}, \pi_{a j}, \pi_{m j}\right\}$, a set of allocations for the firms $\left\{Y_{a j}, Y_{m j}, n_{a j}, n_{m j}, L_{a j}, L_{m j}, z_{a j}\right\}$, a set of allocations for the household $\left\{c_{a j}, c_{m j}\right\}$ such that, (i) given commodity and factor prices, firms' allocations solve the profit maximization problems of firms in each sector, (ii) given prices, the household's allocation solves the utility maximization problem, and (iii) all markets clear, i.e. conditions (23)-(25) are satisfied.

To solve for equilibrium, I normalize the price of the agricultural good to one, $p_{a j}=1$. The form of the preferences implies that consumers will always want to consume some of both goods, and thus both goods will be produced in each region. By perfect mobility of labor across the two sectors the relative price of the manufactured good to the agricultural good is equal to the ratio of the marginal products of labor in farming over manufacturing, $p_{m j}=\alpha \beta\left(Y_{a j} / n_{a j}\right) / \sigma\left(Y_{m j} / n_{m j}\right)$. The first order condition of the farmer's problem with respect to intermediate inputs implies that the optimal intermediate input intensity depends on the relative price of manufacture, $z_{a j} / Y_{a j}=(1-\beta) / p_{m j}$. Combining these two conditions with the agricultural production function (2) and the labor market clearing condition (25) we can solve for the intermediate input intensity in terms of the labor share employed in farming,

$$
\frac{z_{a j}}{Y_{a j}}=\left[\frac{\sigma(1-\beta)}{\alpha \beta} \frac{A^{1-\alpha} \varepsilon_{m j}}{\varepsilon_{a j}^{\alpha}} \frac{\left(L_{m j} / n_{j}\right)^{1-\sigma}}{\left(L_{a j} / n_{j}\right)^{1-\alpha}} \frac{\left(n_{a j} / n_{j}\right)^{1-\alpha}}{\left(1-n_{a j} / n_{j}\right)^{1-\sigma}}\right]^{\beta}
$$

It turns out that all other variables can be expressed in terms of the labor share employed in farming: the wage rate, $w_{j}=\sigma p_{m j} A \varepsilon_{m j}\left(1-n_{a j} / n_{j}\right)^{1-\sigma}\left(L_{m j} / n_{j}\right)^{1-\sigma}$, land rents from agriculture $\pi_{a j}=(1-\alpha) \beta\left(Y_{a j} / L_{a j}\right)$, land rents from manufacturing $\pi_{m j}=p_{m j}(1-\sigma)\left(Y_{m j} / L_{m j}\right)$, and per capita income, $y_{j}=\frac{1}{n_{j}}\left\{w_{j} n_{j}+\pi_{a j} L_{a j}+\pi_{m j} L_{m j}\right\}$.

From the market clearing condition for the agricultural good, (23), the consumption demand for the agricultural good, (13), and the agricultural production function, (2) along with (26), a single non-linear equation with one unknown, $n_{a j} / n_{j}$, can be derived, 


$$
\begin{aligned}
& \bar{a}+\phi\left(y_{j}-\bar{a}\right) \\
= & A^{1-\beta(1-\alpha)}\left[\varepsilon_{a j}^{\alpha}\left(\frac{L_{a j}}{n_{j}}\right)^{1-\alpha}\right]^{\beta}\left[\varepsilon_{m j}\left(\frac{L_{m j}}{n_{j}}\right)^{1-\sigma}\right]^{1-\beta}\left(\frac{\sigma(1-\beta)}{\alpha \beta}\right)^{1-\beta} \frac{\left(\frac{n_{a j}}{n_{j}}\right)^{1-\beta(1-\alpha)}}{\left(1-\frac{n_{a j}}{n_{j}}\right)^{(1-\sigma)(1-\beta)}}
\end{aligned}
$$

Autarkic equilibria are solved for numerically in Section 4, but in Section 3.5 a simpler analytical example is presented.

\subsection{Trade Equilibrium With Incomplete Specialization}

A trade equilibrium in which the East exports the manufacturing good and the West exports the agricultural good requires that the East has a comparative advantage in manufacturing. This pattern of trade will occur when $p_{m E}^{a u t}<p_{m W}^{a u t}$, where aut. stands for the value of the variable under an autarkic equilibrium. This implies some relationship across regions, between TFPs and land to population ratios in both sectors. The following proposition specifies the conditions for comparative advantage in the absence and the presence of subsistence food consumption.

Proposition 1. If $\bar{a}=0$, the East has a comparative advantage in manufacturing if,

$$
\frac{\varepsilon_{m E}}{\varepsilon_{m W}}\left(\frac{L_{m E} / n_{E}}{L_{m W} / n_{W}}\right)^{1-\sigma}>\left(\frac{\varepsilon_{a E}}{\varepsilon_{a W}}\right)^{\alpha}\left(\frac{L_{a E} / n_{E}}{L_{a W} / n_{W}}\right)^{1-\alpha}
$$

If $\bar{a}>0$, the East has a comparative advantage in manufacturing if,

$$
\frac{\varepsilon_{m E}}{\varepsilon_{m W}}\left(\frac{L_{m E} / n_{E}}{L_{m W} / n_{W}}\right)^{1-\sigma} \frac{\left[1-\left(\frac{n_{a W}}{n_{W}}\right)^{a u t .}\right]^{1-\sigma}}{\left[\left(\frac{n_{a W}}{n_{W}}\right)^{a u t .}\right]^{1-\alpha}}>\left(\frac{\varepsilon_{a E}}{\varepsilon_{a W}}\right)^{\alpha}\left(\frac{L_{a E} / n_{E}}{L_{a W} / n_{W}}\right)^{1-\alpha} \frac{\left[1-\left(\frac{n_{a E}}{n_{E}}\right)^{\text {aut. }}\right]^{1-\sigma}}{\left[\left(\frac{n_{a E}}{n_{E}}\right)^{\text {aut. }}\right]^{1-\alpha}}
$$

where $\left(\frac{n_{a j}}{n_{j}}\right)^{\text {aut. }}$ is the solution to $\frac{n_{a j}}{n_{j}}$ in the autarkic equilibrium of region $j$.

Proof. See Appendix B.

The subsistence constraint makes the share of labor in agriculture, a function of farming labor productivity. It turns out that in equilibrium, $\left(\frac{n_{a j}}{n_{j}}\right)^{a u t}$. is a function of the vector of region specific TFPs and land to population ratios, $\left(\varepsilon_{a j}, \varepsilon_{m j}, \frac{L_{m j}}{n_{j}}, \frac{L_{a j}}{n_{j}}\right)$. The model is 
calibrated so that the condition $p_{m E}^{a u t .}<p_{m W}^{a u t .}$ holds, and therefore agricultural goods will always flow from the West to the East in the calibrated model. Next, I define the trade equilibrium with incomplete specialization.

Definition 2. A trade equilibrium with incomplete specialization is a set of commodity prices and freight costs $\left\{p_{a W}, p_{m W}, p_{a E}, p_{m E}, p_{t W}, p_{t E}\right\}$, a set of factor returns $\left\{w_{W}, \pi_{a W}, \pi_{m W}\right.$, $\left.w_{E}, \pi_{a E}, \pi_{m E}\right\}$, a set of allocations for the firms in the West $\left\{Y_{a W}, Y_{m W}, Y_{t W}, n_{a W}, n_{m W}\right.$, $\left.n_{t W}, L_{a W}, L_{m W}, z_{a W}, t_{a W}\right\}$, a set of allocations for the firms in East $\left\{Y_{a E}, Y_{m E}, Y_{t E}, n_{a E}\right.$, $\left.n_{m E}, n_{t E}, L_{a E}, L_{m E}, z_{a E}, t_{m E}\right\}$, a set of allocations for the households $\left\{c_{a W}, c_{m W}, c_{a E}, c_{m E}\right\}$, a set of trade flows $\left\{M_{a E}, M_{m W}, X_{a W}, X_{m E}\right\}$ such that, (i) given commodity and factor prices, firms' allocations solve the profit maximization problems of firms in every sector in each region, (ii) given prices, the households' allocation solve the utility maximization problems, and (iii) all markets clear, i.e. conditions (15)-(22) are satisfied.

To solve for equilibrium, I normalize the price of the agricultural good in the West to be one, $p_{a W}=1$. From the farmer's profit maximizing conditions with respect to labor and intermediate inputs, the wage rate in the West is

$$
w_{W}=\alpha \beta\left(A \varepsilon_{a W}\right)^{\alpha}\left(\frac{n_{a W}}{n_{W}}\right)^{\alpha-1}\left(\frac{L_{a W}}{n_{W}}\right)^{1-\alpha}\left(\frac{1-\beta}{p_{m W}}\right)^{\frac{1-\beta}{\beta}}
$$

From the first order condition with respect to labor in manufacturing and the condition for wage equalization across sectors, the relative price of the manufactured good in the West is,

$$
p_{m W}=(1-\beta)^{1-\beta}\left(\frac{\alpha \beta \varepsilon_{a W}^{\alpha}}{\sigma A^{1-\alpha} \varepsilon_{m W}} \frac{\left(L_{a W} / n_{W}\right)^{1-\alpha}}{\left(L_{m W} / n_{W}\right)^{1-\sigma}} \frac{\left(n_{m W} / n_{W}\right)^{1-\sigma}}{\left(n_{a W} / n_{W}\right)^{1-\alpha}}\right)^{\beta}
$$

The wage equalization condition between the manufacturing sector and the transportation sector, means that the relative cost of transporting goods from the West to the East is,

$$
p_{t W}=\sigma p_{m W} \frac{A \varepsilon_{m W}}{A_{t}}\left(\frac{L_{m W} / n_{W}}{n_{m W} / n_{W}}\right)^{1-\sigma}
$$

From the pricing function of the exporter in the West, (12), the price of the agricultural good in the East will be $p_{a E}=\left(1 / \varphi_{a}\right)\left(1+p_{t W}\right)$.

The farmer's profit maximizing conditions in the East imply that the wage rate in the East is, 


$$
w_{E}=p_{a E}^{\frac{1}{\beta}} \alpha \beta\left(A \varepsilon_{a E}\right)^{\alpha}\left(\frac{n_{a E}}{n_{E}}\right)^{\alpha-1}\left(\frac{L_{a E}}{n_{E}}\right)^{1-\alpha}\left(\frac{1-\beta}{p_{m W}}\right)^{\frac{1-\beta}{\beta}}
$$

Wage equalization between manufacturing and farming in the East implies that the relative price of the manufactured good in the East is,

$$
p_{m E}=p_{a E}(1-\beta)^{1-\beta}\left(\frac{\alpha \beta \varepsilon_{a E}^{\alpha}}{\sigma A^{1-\alpha} \varepsilon_{m E}} \frac{\left(L_{a E} / n_{E}\right)^{1-\alpha}}{\left(L_{m E} / n_{E}\right)^{1-\sigma}} \frac{\left(n_{m E} / n_{E}\right)^{1-\sigma}}{\left(n_{a E} / n_{E}\right)^{1-\alpha}}\right)^{\beta}
$$

and wage equalization between manufacturing and transportation requires that the relative freight cost for transporting manufactured goods from the East to the West is,

$$
p_{t E}=\sigma p_{m E} \frac{A \varepsilon_{m E}}{A_{t}}\left(\frac{L_{m E} / n_{E}}{n_{m E} / n_{E}}\right)^{1-\sigma}
$$

From the pricing function of the exporter in the East the relative price of imported manufactured goods in the West is, $p_{m W}^{t r .}=\left(1 / \varphi_{m}\right)\left(p_{m E}+p_{t E}\right)$. The existence of a trade equilibrium in which the West is incompletely specialized requires that the relative prices of the domestically produced and the imported manufactured goods are equal, $p_{m W}^{t r}=p_{m W}$.

From the market clearing conditions with respect to agriculture for the two regions, (17) and (21), the economy-wide market clearing condition for agriculture requires that the total amount of per capita food consumed in the two regions is equal to the weighted average of farm productivities (appropriately adjusted for regional population sizes and iceberg costs),

$$
c_{a W}+\frac{1}{\varphi_{a}} \cdot \frac{n_{E}}{n_{W}} \cdot c_{a E}=\frac{Y_{a W}}{n_{a W}} \cdot \frac{n_{a W}}{n_{W}}+\frac{1}{\varphi_{a}} \cdot \frac{n_{E}}{n_{W}} \cdot \frac{Y_{a E}}{n_{a E}} \cdot \frac{n_{a E}}{n_{E}}
$$

where per capita consumption in each region is given by, (13). Using a similar logic one can derive the economy wide market clearing condition for manufacturing. By Walraw's law only one of the two is needed to solve for equilibrium.

The market clearing conditions for transportation and the Leontief nature of the exporting technologies require that the total amount of transportation services produced in each region are equal to the total amount of exports,

$$
A_{t} \cdot\left(1-\frac{n_{a E}}{n_{E}}-\frac{n_{m E}}{n_{E}}\right)=\frac{Y_{m E}}{n_{m E}} \cdot \frac{n_{m E}}{n_{E}}-\frac{z_{a E}}{Y_{a E}} \cdot \frac{Y_{a E}}{n_{a E}} \cdot \frac{n_{a E}}{n_{E}}-c_{m E}
$$




$$
A_{t} \cdot\left(1-\frac{n_{a W}}{n_{W}}-\frac{n_{m W}}{n_{W}}\right)=\frac{Y_{a W}}{n_{a W}} \cdot \frac{n_{a W}}{n_{W}}-c_{a W}
$$

where, I have also used the transportation production functions, and the labor market clearing conditions (15) and (19).

Equations (27)-(29) along with $p_{m W}^{t r}=p_{m W}$ constitute a system of four non-linear equations in four unknowns, $\frac{n_{a W}}{n_{W}}, \frac{n_{m W}}{n_{W}}, \frac{n_{a E}}{n_{E}}, \frac{n_{m E}}{n_{E}}$, which I solve for numerically. This is also the system of equations used to trace the equilibrium responses of all the endogenous variables to an exogenous change in the transportation TFP parameter $A_{t}$. In the next section, I consider a simpler version of the model to show some analytical results.

\subsection{The Role of Transportation TFP: A Simple Illustration}

To obtain an insight into the role of transportation TFP for the level and the composition of productivity, I consider here a simple case analytically. In particular, there are no decreasing returns in manufacturing $(\sigma=1)$ or agriculture $(\alpha=1)$, there are no intermediate inputs $(\beta=1)$, and the demand for the agricultural good is determined solely by the subsistence food requirement $(\phi=0)$.

Under these assumptions the production technologies for the agricultural and the manufactured goods, in each region $j$, are linear in labor: $Y_{a j}=A \varepsilon_{a j} n_{a j}$ and $Y_{m j}=A \varepsilon_{m j} n_{m j}$. The con-

dition for the West's comparative advantage in farming reduces to $\frac{\varepsilon_{a W}}{\varepsilon_{m W}}>\frac{\varepsilon_{a E}}{\varepsilon_{m E}}$. Furthermore, consumers in each region now consume only $c_{a j}=\bar{a}$ of the agricultural good and devote the rest of their income to the consumption of the manufactured good, $c_{m j}=\frac{1}{p_{m j}}\left(w_{j}-\bar{a} \cdot p_{a j}\right)$. I will focus on a trade equilibrium, in which the West is completely specialized in the production of the agricultural good, while the East is incompletely specialized (produces both goods but also imports some of its food from the West).

Consider first an autarkic equilibrium, in which each region produces its own agricultural and manufactured goods. With the agricultural good being the numeraire in each region $j$, the wage rate is $w_{j}=A \varepsilon_{a j}$, and the relative price of manufacturing is $p_{m j}=\frac{\varepsilon_{a j}}{\varepsilon_{m j}}$. The market clearing condition for the agricultural commodity, (23), implies that in an autarkic equilibrium, the share of labor allocated to agricultural production in each region $j$ is,

$$
\frac{n_{a j}}{n_{j}}=\frac{\bar{a}}{A \varepsilon_{a j}}
$$


This says that, in the presence of a subsistence constraint in food consumption, the share of labor that each region devotes to the agricultural sector depends negatively on the productivity in farming. Intuitively, when an activity is distorted, agents will substitute away from that activity thereby lessening the impact of the distortion. Due to the subsistence constraint in food consumption agents cannot substitute away from farming, but instead have to devote even more resources to farming. Therefore, in autarky, the region which is less productive in agriculture has to devote more resources to farm production, other things equal.

The negative relationship between the share of labor in agriculture and farming productivity is Schultz's (1953) main insight. If however, the two regions can trade, then the region that is unproductive in farming can circumvent its low productivity by simply importing agricultural goods from the productive region. Thus, one would expect that the close link between agricultural productivity and resources devoted to that activity should be weakened, as static gains from trade are realized. To see this, consider the market clearing condition for the agricultural good in the East under trade, (21). It can be re-arranged as follows:

$$
\frac{n_{a E}}{n_{E}}=\frac{\bar{a}-\frac{M_{a E}}{n_{E}}}{Y_{a E} / n_{a E}}
$$

where $M_{a E} / n_{E}$ are the per capita imports of food in the East from the West. From (31) it is clear that the share of labor devoted to farming in the East depends on the productivity of the local agricultural sector only to the extent that the local food requirements are not covered by imports. In the extreme case, in which all subsistence consumption is met by imports, i.e., $M_{a E} / n_{E}=\bar{a}$, the connection between the labor share in farming and agricultural labor productivity disappears.

For the economy as a whole, which consists of both regions, the share of labor devoted to agricultural production is,

$$
\frac{n_{a}}{n}=\frac{\bar{a} \cdot\left(1+\frac{1}{\varphi_{a}} \cdot \frac{n_{E}}{n_{W}}\right)}{\frac{Y_{a W}}{n_{a W}} \cdot \frac{n_{a W}}{n_{a}}+\frac{1}{\varphi_{a}} \cdot \frac{n_{E}}{n_{W}} \cdot \frac{Y_{a E}}{n_{a E}} \cdot\left(1-\frac{n_{a W}}{n_{a}}\right)}
$$

where $n=n_{E}+n_{W}$ and $n_{a}=n_{a E}+n_{a W}$. To derive (32) I have used (17) and (21). Equation (32) is similar to its autarky counterpart, only that the share of labor devoted to farming under trade depends on the weighted average of farming productivities of the two regions. 
Thus $n_{a} / n$ depends not only on how productive farming is in each region but also on the mix of farming activity between the two regions. A key insight of (32) is that, the more farming takes place in the region most suited for farming (i.e., the higher $n_{a W} / n_{a}$ ), the smaller the weight of agriculture in economic activity.

Transportation TFP plays a key role for the level and the composition of productivity because it affects the extent of trade between the two regions. The effects of a change in transportation TFP are summarized in the following proposition.

Proposition 2. An increase in transportation TFP, $A_{t}$, (i) raises average agricultural labor productivity, (ii) reduces the economy-wide share of labor employed in agriculture, (iii) raises aggregate labor productivity.

The solution of equilibrium along with the effect of an increase in transportation TFP on the equilibrium allocations and relative prices is provided in Appendix B. Here I outline the main intuition. Farming productivity for the whole country is given by,

$$
\frac{Y_{a}}{n_{a}}=\frac{Y_{a W}}{n_{a W}} \cdot \frac{n_{a W}}{n_{a}}+\frac{Y_{a E}}{n_{a E}} \cdot\left(1-\frac{n_{a W}}{n_{a}}\right)
$$

An increase in transportation TFP, reduces the freight cost of shipping goods across the two regions. Since trade becomes more "free", regions will specialize and produce more according to comparative advantage. The West will produce more of the agricultural good to export to the East. This alters the mix of farming activity across the two regions, with a relocation of farming towards the more productive region. This will raise average agricultural productivity in the economy.

The average labor productivity in manufacturing for the whole economy, in this version of the model is $Y_{m} / n_{m}=A \varepsilon_{m E}$ (since only the East produces manufactured goods) and is not affected by a change in transportation TFP.

Aggregate productivity will increase in the economy because of the increase in transportation and farming productivities,

$$
\frac{Y}{n}=\frac{Y_{a}}{n_{a}} \cdot \frac{n_{a}}{n}+p_{m}^{*} \cdot \frac{Y_{m}}{n_{m}} \cdot \frac{n_{m}}{n}+p_{t}^{*} \cdot \frac{Y_{t}}{n_{t}} \cdot \frac{n_{t}}{n}
$$

where manufactured goods and transportation services are valued at some common set of relative prices $\left(p_{m}^{*}, p_{t}^{*}\right)$. A higher average agricultural productivity means that the economy 
wide share of labor employed in agriculture will fall as a result of the increase in transportation TFP - see (32). The intuition is the following. There is a given amount of agricultural goods that have to be produced in the economy to meet the subsistence needs of the population in both regions. The more productive you are in farming the fewer resources will be required to meet these subsistence needs. Also, the Leontief nature of the export technologies implies that as a result of the increase in TFP in the transportation sector, the share of labor devoted to transporting goods will fall in both regions.

In order to have a trade equilibrium in which the West produces only the agricultural good and the East produces both goods, the following conditions have to be satisfied: (1) it must not be worth for the West to produce the manufacturing good at home, $p_{m W}^{t r}<p_{m W}^{a u t}$ the superscripts aut. and $t r$. stand for equilibria under autarky and trade respectively, and (2) the relative cost of producing the manufacturing good should be the same for East as the relative cost of trading, $p_{m E}^{a u t .}=p_{m E}^{t r .} / p_{a E}^{t r .}$. Inefficiencies in the transportation sector, manifested through a lower $A_{t}$, raise $p_{m W}^{t r}$, making the first condition less likely to hold. In particular it is less likely that it will be worth for the West to import $m$ rather than produce it locally. As shown in Appendix B, the second condition will always hold. The following proposition summarizes this idea.

Proposition 3. If $A_{t}<\bar{A}_{t}$ no trade will take place between the two regions even if in a transportation free world it would.

Proof. See Appendix B.

There is a cutoff level of transportation TFP $\bar{A}_{t}$, below which it is not profitable for the two regions to trade. If $A_{t}$ falls below the cutoff, the two regions behave as autarkic economies. In the next section the complete version of the model is calibrated and simulated for each economy in my data set.

\section{Quantitative Analysis}

In this section, I quantitatively assess the role of transportation TFP in accounting for the observed cross-country differences in aggregate labor productivity, agricultural labor productivity, the share of labor in agriculture, and the intermediate input intensity. The section also 
contains sensitivity analysis, and a set of policy experiments aimed at assessing the benefits from improvements in transportation TFP, for developed and developing countries.

\subsection{Calibration}

I calibrate the benchmark economy to 1985 U.S. sectoral, regional and aggregate data so that the benchmark data set is a trade equilibrium of the model with incomplete specialization. The parameters that need to be determined are: TFP parameters $\left(A, \varepsilon_{a E}, \varepsilon_{a W}, \varepsilon_{m E}, \varepsilon_{m W}\right.$, $\left.A_{t}\right)$, production function elasticity parameters $(\alpha, \beta, \sigma)$, preference parameters $(\phi, \bar{a})$, and regional land to population ratios $\left(L_{a E} / n_{E}, L_{a W} / n_{W}, L_{m E} / n_{E}, L_{m W} / n_{W}\right)$. I normalize iceberg costs to unity, $\varphi_{a}=\varphi_{m}=1$, i.e., whatever is shipped fully makes it to the other region.

Mapping the model to the data requires a division of the U.S. states into East and West. In the data I take the East to include New England (Maine, New Hampshire, Vermont, Massachusetts, Rhode Island and Connecticut) and Middle Atlantic (New York, New Jersey and Pennsylvania), and the West to include the rest ${ }^{19}$ of the U.S. states except for D.C., Alaska and Hawaii. Although any such division is somewhat arbitrary, the criterion here has been to have a geographical East with a comparative advantage in non-agriculture and a geographical West with a comparative advantage in agriculture.

To construct regional values for the variables of interest I use: (1) aggregate U.S. data from international data sources (PWT, FAO), (2) state level data from the Bureau of Economic Analysis (BEA), the U.S. Department of Agriculture (USDA), and the Statistical Abstract of the United States (SAUS). The aggregate U.S. data from the PWT and the FAO have the advantage of being directly comparable to data of other countries. The state level data allow me to construct for every variable the ratio of values between the West and the East. The (internationally comparable) regional values are constructed by using an accounting decomposition of the aggregate variables. For example, aggregate agricultural productivity

\footnotetext{
${ }^{19}$ In particular, the West includes East North Central (Ohio, Indiana, Illinois, Michigan, Wisconsin), West North Central (Minnesota, Iowa, Missouri, North Dakota, South Dakota, Nebraska, Kansas), South Atlantic (Delaware, Maryland, Virginia, West Virginia, North Carolina, South Carolina, Georgia, Florida), East South Central (Kentucky, Tennessee, Alabama, Mississippi), West South Central (Arkansas, Louisiana, Oklahoma, Texas), Mountain (Montana, Idaho, Wyoming, Colorado, New Mexico, Arizona, Utah, Nevada), and Pacific (Washington, Oregon, California).
} 
is decomposed as follows,

$$
\frac{G D P_{a}}{n_{a}}=\frac{G D P_{a E}}{n_{a E}} \cdot\left(1-\frac{n_{a W}}{n_{a}}\right)+\frac{G D P_{a W}}{n_{a W}} \cdot \frac{n_{a W}}{n_{a}}
$$

I use data on aggregate agricultural productivity, $G D P_{a} / n_{a}$ from the FAO and average state level data on relative regional agricultural productivity, $\frac{G D P_{a W} / n_{a W}}{G D P_{a E} / n_{a E}}=1.96$, from Ball, Butault, and Nehring (2001) of the USDA. The share of Western agricultural labor input (persons employed) in total agricultural labor input, $n_{a W} / n_{a}=0.914$, is calculated with data from the SAUS. Then the regional agricultural productivities $G D P_{a E} / n_{a E}$ and $G D P_{a W} / n_{a W}$ can be calculated by re-arranging equation (33). Using $n_{a W} / n_{a}$ from above and the total economically active population engaged in U.S. agriculture from the FAO, $n_{a}$, I calculate the total number of people engaged in agriculture in each region $\left(n_{a W}\right.$ and $\left.n_{a E}\right)$.

The $m$ sector of the model economy is taken to be in the data not only the manufacturing sector but the rest of the economy except for the agricultural and the transportation sectors. This distinction is kept when calculating the $m$ sector counterparts to equation (33). Based on data from the BEA and SAUS, ${ }^{20}$ relative regional productivity is $\frac{G D P_{m W} / n_{m W}}{G D P_{m E} / n_{m E}}=0.97$, and the share of Western labor input in total sectoral input is $n_{m W} / n_{m}=0.772$. At the international level, $G D P_{m} / n_{m}$ is calculated as the non-agricultural sector using data from the FAO and the PWT.

The labor endowments, $n_{E}$ and $n_{W}$, are calculated using the ratio of total number of persons employed in the West vs. the East $\left(n_{W} / n_{E}=3.66\right)$, obtained from the SAUS, and the aggregate "persons employed" figure for the U.S., $n$, from PWT data.

Combining state level data on relative regional farm land acreage, $L_{a W} / L_{a E}=33.2$, from the USDA and total arable U.S. land, $L_{a}$, from the FAO, I calculate the regional arable land endowments, $\left(L_{a E}, L_{a W}\right)$. The above decomposition ensures that the aggregate arable land to population ratio is equal to 1.62, which is the value for the U.S. economy based on the international data. The arable land to population ratios calculated for the East and the West are 0.22 and 2 .

The labor elasticity in agriculture, $\alpha$, is chosen to be 0.7 which is within the ballpark of estimates of agricultural production functions, as reported by Hayami and Ruttan (1985)

\footnotetext{
${ }^{20}$ These numbers are almost identical if instead I calculate the $m$ sector as inclusive of transportation.
} 
among others. The parameter $\beta$ is set at 0.6 to match an intermediate input to agricultural output ratio in the U.S. economy of 0.4 , as reported by the FAO. $\sigma$ is set equal to 0.94 to match a share of land in the manufacturing sector of 0.06 as reported by Caselli and Coleman (2001), based on data from the Bureau of Labor Statistics.

The economy-wide TFP parameter $A$ is set equal to non-agricultural real GDP per worker. Due to lack of comparable international data on non-agricultural land, the land-population term in the non-agricultural production function is included in the sector-specific TFP term. The adjusted TFP terms to be determined are then, $\widehat{\varepsilon}_{m j}=\varepsilon_{m j}\left(L_{m j} / n_{j}\right)^{1-\sigma}$ for $j \in\{E, W\}$. The technological parameters $\varepsilon_{a E}, \varepsilon_{a W}, \widehat{\varepsilon}_{m E}, \widehat{\varepsilon}_{m W}$, are chosen residually to match sectoral labor productivities by region. The transportation TFP parameter $A_{t}$ is chosen to match a share of intercity rail and truck transportation in consumer expenditures on food and transportation of 0.16 (transportation margin), based on 1985 data from the USDA.

In the model $\phi$ determines the long-run share of agricultural labor. ${ }^{21}$ Following Restuccia, Yang and Zhu (2004) I set $\phi=0.005$ to match a long-run employment share in agriculture of $0.5 \%$. The subsistence parameter $\bar{a}$ is chosen to match an aggregate share of labor in agriculture of $2.85 \%$ for the US economy in 1985 (FAO data). The calibrated parameters, along with their values and targets are summarized in Table 1.

Table 1: Calibrated Parameter Values

\begin{tabular}{ccl}
\hline Parameter & Value & Target \\
\hline$A$ & 34,206 & Labor productivity in nonagriculture \\
$A_{t}$ & 73,380 & Food transportation margin \\
$\varepsilon_{a W}$ & 13.6 & Agricultural productivity in the West \\
$\varepsilon_{a E}$ & 5.02 & Agricultural productivity in the East \\
$\widehat{\varepsilon}_{m W}$ & 1.16 & Nonagricultural productivity in the West \\
$\widehat{\varepsilon}_{m E}$ & 1.02 & Nonagricultural productivity in the East \\
$L_{a W} / n_{W}$ & 2 & Land to population ratio - West \\
$L_{a E} / n_{E}$ & 0.22 & Land to population ratio - East \\
$\alpha$ & 0.7 & Hayami and Ruttan (1985) \\
$\beta$ & 0.6 & Intermediate input share - FAO \\
$\sigma$ & 0.94 & Caselli and Coleman (2001) \\
$\bar{a}$ & 844 & 1985 agricultural labor share for the US \\
$\phi$ & 0.005 & Long-run share of labor in farming \\
\hline
\end{tabular}

\footnotetext{
${ }^{21} \phi$ would be the value that the agricultural labor share would attain in the steady state of the dynamic version of the model.
} 
The above data imply that the relative cost of producing manufactured goods in the East is lower than in the West, $p_{m E}^{a u t}<p_{m W}^{a u t}$. That is the East has a comparative advantage in manufacturing, confirming that a trade equilibrium with transportation exists.

\subsection{Quantitative Results}

I assume that countries are closed economies and otherwise identical to the benchmark except in the following dimensions: economy-wide TFP $A$, transportation TFP $A_{t}$, and land to population ratios $L_{a} / n$.

For each country $i, A_{i}$ is calculated as non-agricultural real GDP per worker based on data from the FAO and the PWT. The transportation TFP parameter for each country $i$, $A_{t, i}$, is calculated based on the relative transportation infrastructure index (TII), which was

discussed in Section 2, and the U.S. transportation TFP as follows: $A_{t, i}=\left(\frac{T I I_{i}}{T I I_{u s}}\right) A_{t, u s}$. The two regional land to population ratios for each country $i$, are constructed from the aggregate land to population ratio from the $\mathrm{FAO}, L_{a i} / n_{i}$, assuming that cross-regional differences are as large as the U.S. ones.

For each country in my sample I compute the equilibrium economy-wide labor share in agriculture $n_{a} / n$, the economy-wide agricultural productivity $Y_{a} / n_{a}$, the aggregate productivity $Y / n$, and the economy-wide intermediate input intensity in agriculture $z_{a} / Y_{a}$, using the relative prices of the benchmark economy as the international prices. Note, that these equilibrium values do not necessarily correspond to trade equilibria with incomplete specialization for all of the countries in the sample. If for a given country a trade equilibrium with incomplete specialization does not exist (due to low transport TFP) then the equilibrium values correspond to the values obtained from the autarkic regional equilibria for that country.

Then the question I ask is the following: how much of the cross-country differences in $n_{a} / n$, $Y_{a} / n_{a}, Y / n, z_{a} / Y_{a}$ that we observe in the data, can the model account for, with exogenous differences in $A, L_{a} / n, A_{t}$. I compare, for each variable, the ratio of the $5 \%$ rich to the $5 \%$ poor from the data to the "computed" one from the model.

Table 2 presents the results for the benchmark model, along with the data and a counterfactual without transportation. In the data the average $5 \%$ richest countries in the sample have an aggregate labor productivity that is 32.4 times that of the average $5 \%$ poorest. The 
predicted disparity for aggregate labor productivity in the model between these same groups of countries is 10.9. Thus the model with transportation and agriculture accounts for over $1 / 3$ of the observed aggregate labor productivity disparity and does 35\% better than a two-sector model (agriculture, non-agriculture) with the same economy-wide productivity differences (A) and economy-wide land to population ratios $\left(L_{a} / n\right)$.

The benchmark model predicts a disparity in agricultural final output per worker of 12.4, 27\% higher than the 9.8 disparity predicted by the two-sector model. The model also does better than the two-sector model in accounting for the large differences in agricultural employment shares across countries. It is not successful in accounting for the disparities in intermediate input use at the aggregate level. In particular it predicts that poor countries have higher intermediate input intensities than rich countries. The reason is that, in the model, high land to population ratios deter farmers from using intermediate inputs. As will be seen however a transportation improvement induces the region of a country that specializes in agriculture to increase its use of intermediate inputs.

\begin{tabular}{lllll} 
Table 2: Ratio of Average 5\% Rich to Average 5\% \\
\cline { 2 - 6 } & $\frac{Y}{n}$ & $\frac{Y_{a}}{n_{a}}$ & $\frac{n_{a}}{n}$ & $\frac{z_{a}}{Y_{a}}$ \\
\hline Data & 32.4 & 99.8 & 0.06 & 3.2 \\
Model & 10.9 & 12.4 & 0.09 & 0.8 \\
Counterfactual & & & & \\
Two-sector & 8.1 & 9.8 & 0.12 & 1.0 \\
\hline
\end{tabular}

These results imply that differences in transportation TFP across countries play a nontrivial role in understanding cross-country differences in aggregate and agricultural productivity and employment shares across countries. The reason that the model with transportation performs better, is that inefficiencies in transportation systems can distort aggregate productivity through three channels: (i) directly, since value added in transportation is part of GDP, (ii) by reducing average industry labor productivity, since transportation inefficiencies prevent regions from trading based on comparative advantage, and (iii) by altering the weight that each sector carries in aggregate output. In particular, a lower TFP in transportation means that each region has to produce more of its own food. This is a problem for the region that is less productive in agriculture because it has to devote even more labor to farming (due to the subsistence constraint) than would have otherwise if the productive region produced all the food and the two regions traded. Also due to the Leontief nature of the export tech- 
nologies, an inefficiency in transportation means that even more workers are needed to deliver a given amount of traded goods, which also precludes the release of labor to non-agriculture.

\subsection{Discussion}

In the benchmark experiment, the region specific agricultural TFP parameters have been calibrated to U.S. cross-regional agricultural labor productivity differences. How do U.S. productivity differences compare to the actual ones within developing countries? In general, productivity data for different regions within each country, are not available, for the large set of countries in my sample. While data availability is an issue in general, India has good and detailed data by state and sector. I calculate agricultural labor productivities for India's 14 major states, using data mainly from the World Bank's Database on Poverty and Growth in India (see Appendix A for details). In Table A.3, in Appendix A, I report agricultural labor productivity for each state relative to the level of productivity in Uttar Pradesh, which is the state that produces the largest share of India's agricultural output. Table A.3 indicates that productivity differences in agriculture are quite large across Indian states, in fact larger than the U.S. regional ones. The 4 most productive states have an average labor productivity in agriculture that is 2.6 times higher than the average for the 4 least productive ones. Furthermore, as the second column of Table A.3 reveals, the most productive states produce almost the same fraction of the country's agricultural output as the least productive ones (34\% vs. $31 \%)$.

These numbers suggest that a re-allocation of agricultural production across Indian states can raise agricultural productivity at the aggregate level. In section 4.4, I consider the quantitative effect on India's productivity from an improvement in its transportation system.

\subsection{Experiments}

Next, I want to assess the quantitative impact on a country's aggregate productivity, agricultural productivity, employment allocation, and intermediate input intensity use, from improving transportation TFP. I undertake three experiments. The message from the three experiments is that the effects of transportation improvements are non-linear, that is, poor countries are much more likely to benefit than rich countries. This is important from a pol- 
icy standpoint because it suggests that a dollar spent on transportation infrastructure in a developing country will go a longer way than in a developed country.

Experiment 1: Developed Country (United States) In the first experiment I examine the effect from varying TFP in the benchmark economy, the 1985 United States. I find that doubling transportation TFP, reduces transportation costs $50 \%$, increases agricultural productivity $2.9 \%$, has almost no effect on the share of labor in agriculture for the whole economy, increases intermediate input intensity in the agricultural producing region by $0.8 \%$, and increases aggregate productivity by $0.4 \%$. In other words the effects from doubling transportation TFP in today's U.S. are minimal. The first row of Table 3 summarizes these results.

Table 3: Changes from doubling TFP in the United States and India

\begin{tabular}{lccccc}
\hline & $\% \Delta\left(\frac{Y}{n}\right)$ & $\% \Delta\left(\frac{Y_{a}}{n_{a}}\right)$ & $\Delta\left(\frac{n_{a}}{n}\right)$ & $\% \Delta\left(\frac{z_{a}}{Y_{a}}\right)$ & $\% \Delta\left(\frac{z_{a W}}{Y_{a W}}\right)$ \\
\hline United States & 0.4 & 2.9 & $-0.0 \%$ & -2 & 0.8 \\
India & 7.1 & 11.1 & $-1.8 \%$ & -6.8 & 6.1 \\
\hline
\end{tabular}

There are two reasons that improvements in transportation have little impact beyond some point. First, the US is far from subsistence, and consequently there is little interaction between transport TFP and the labor share in agriculture. Second, in the model, once transportation TFP has improved enough, that transport costs are very low, the country is in a near free trade state. Further improvements cannot increase trade more that what is associated with free trade. Thus the productivity benefits for rich countries, like the U.S., are small.

The reason that the economy-wide intermediate input intensity drops after an increase in transportation TFP is the following. There is a large difference between the East and the West in the arable land to population ratios: 2 in the West, 0.22 in the East. At a lower level of transportation TFP and a lower level of regional trade, each region produces more of its own food. In the model, the region with the low land to population ratio will compensate by using intermediate inputs more intensively. When transportation improvements permit a further spatial re-allocation of farming to the West, the East will produce less food. Even though the intermediate input use in the West rises the decline in the East is larger (due to the subsistence constraint), resulting in a decline in the economy-wide intermediate input 
intensity.

Experiment 2: Developing Country (India) Given that the model has been calibrated to 1985 US data, the first experiment cannot fully capture the experience of the developing nations. The reasons are that the US is far from subsistence and that it already has a high transport TFP. In the second experiment I examine the effect from varying transportation TFP in India, a developing country for which I have regional productivity data.

In terms of aggregate GDP per worker, the U.S. is 12.4 times more productive than India. In agriculture, the U.S. is 68.6 times more productive than India. Furthermore, the U.S. devotes only $2.85 \%$ of labor to agriculture, while India devotes $67.6 \%$ of its labor to agriculture. As argued above, the regional productivity differences between the U.S. states and those between the Indian states are similar. In addition, the transportation infrastructure index in the U.S. is 13 times higher than in India. I want to examine to what extent improvements in transportation, can lead to productivity gains in agriculture and the aggregate economy.

To run the experiment I take the West to be Punjab and Harayana, Andhra Pradesh, Gujarat, Maharashtra, and the East to be Assam, Orissa, Bihar, Uttar Pradesh. ${ }^{22}$ For each region I calculate arable land and population endowments, based on the data from the World Bank. Taking regional endowments, Indian economy-wide productivity, and the Indian transportation infrastructure index as given, I ask the following question: what will happen to the variables of interest if I double TFP in the transportation sector.

Doubling transportation TFP in this economy, reduces transportation costs $50 \%$, increases agricultural labor productivity $11.1 \%$, reduces the share of labor in agriculture by 1.8 percentage points for the whole economy, increases intermediate input intensity in the agricultural producing region by $6.1 \%$, and increases aggregate labor productivity by $7.1 \%$. The results are summarized in the second row of Table 3.

Average labor productivity in agriculture increases because the West specializes in producing agricultural goods and the East in producing non-agricultural goods. Because of decreasing returns to labor in farming, labor productivity rises in the East and falls in the

\footnotetext{
${ }^{22}$ The criterion for this division is the level of productivity, with the West being the more productive region. It turns out, however that these two groups correspond to geographical West and East in India too (an exception is Andhra Pradesh, which lies on the East coast).
} 
West. However the increase in the labor productivity in the East is larger in absolute terms than the decrease in the West, because the East was close to subsistence, was unproductive in farming and thus had to devote a large amount of resources to farming. ${ }^{23}$ For this reason the drop in the economy-wide intermediate input use is so large. In the West, which specializes in agriculture the intermediate input intensity increases because now the modern intermediate inputs imported from the East are cheaper due to lower freight costs.

Experiment 2 suggests that given India's current distribution of productivities across states, it can realize sizable productivity gains by improving its transportation system. Together, experiments 1 and 2 illustrate that the effects of changes in transportation TFP are non-linear: poor countries are more likely to benefit from an improvement in transportation TFP than rich countries.

Experiment 3: Elasticities with respect to $A_{t}$ for the full sample In the third experiment I ask the following question: what will be the percentage change in aggregate productivity, agricultural productivity, agricultural labor share, intermediate input intensity if all the countries in the sample had their own economy-wide TFP and land to population ratios but $1 \%$ more transportation TFP than they do in the data? In other words I calculate elasticities of the key variables of interest with respect to transport TFP. These elasticities for the $5 \%$ poorest and richest countries in my sample along with their factor differences are reported in Table 4.

Table 4: Elasticities for Rich and Poor 5\%

\begin{tabular}{lcccc}
\hline & $\frac{Y}{n}$ & $\frac{Y_{a}}{n_{a}}$ & $\frac{n_{a}}{n}$ & $\frac{z_{a}}{Y_{a}}$ \\
\hline Rich 5\% & 0.003 & 0.023 & -0.017 & -0.021 \\
Poor 5\% & 0.045 & 0.243 & -0.204 & -0.230 \\
Ratio & $1 / 15$ & $1 / 10.6$ & $1 / 12.2$ & $1 / 10.9$ \\
\hline
\end{tabular}

The results are stark: While endowing the $5 \%$ rich countries of the world with $1 \%$ more of transportation TFP will raise their aggregate productivity by only 0.003 , the increase would be 15 times larger in the $5 \%$ poor countries of my sample. The factor difference in the elasticity of agricultural labor productivity between the same two sets of countries is 10.6.

\footnotetext{
${ }^{23}$ Notice, that in the special version of the model discussed in Section 3.5, the mechanism through which agricultural labor productivity increased was different because there were no decreasing returns to labor.
} 
The intuition behind these results is that, rich countries already have a very high TFP in transportation and are in a near free trade state and therefore have exploited already whatever internal gains from trade there were to exploit. This again suggests that poor countries are much more likely to benefit from improvements in transportation infrastructure than rich countries. The benefits of increasing the use of intermediate inputs and releasing labor out of agriculture are also larger for the less developed countries.

\subsection{Sensitivity Analysis}

In this section I examine the sensitivity of the model's results to some of the assumptions made in the benchmark calibration. I also consider two counterfactual experiments.

\begin{tabular}{lllll} 
Table 5: Ratio of Average $5 \%$ & Rich to Average $5 \%$ P \\
\cline { 2 - 5 } & $\frac{Y}{n}$ & $\frac{Y_{a}}{n_{a}}$ & $\frac{n_{a}}{n}$ & $\frac{z_{a}}{Y_{a}}$ \\
\hline Benchmark model & 10.9 & 12.4 & 0.09 & 0.8 \\
$\lambda=1.2$ & 11.0 & 12.9 & 0.09 & 0.8 \\
$\lambda=0.8$ & 10.6 & 10.9 & 0.10 & 0.9 \\
$\phi=0$ & 11.2 & 12.5 & 0.08 & 0.8 \\
$\alpha=0.6$ & 12.1 & 13.4 & 0.09 & 0.8 \\
$\sigma=0.8$ & 10.7 & 11.9 & 0.09 & 0.8 \\
$\varphi_{a}=0.9$ & 11.3 & 12.6 & 0.09 & 0.8 \\
$\varphi_{m}=0.9$ & 11.2 & 12.4 & 0.09 & 0.8 \\
\hline US land/pop. ratio & 9.7 & 9.9 & 0.11 & 0.96 \\
no interm. inputs & 7.7 & 10.8 & 0.18 & - \\
\hline
\end{tabular}

TFP specification in transportation technology The specification of the technology for producing transport services, (3), implicitly assumes that the elasticity of transportation output per worker with respect to transportation infrastructure is equal to one. To evaluate the importance of this assumption, I specify a more general production function for transport services, $Y_{j t}=A_{t}^{\lambda} n_{j t}$. When $\lambda=1$, the transportation production function is identical to the one used in the benchmark experiments. To assess the quantitative impact of different values of $\lambda$, I compute and report in Table 5 the differences, in the key variables of interest, between the $5 \%$ rich and poor countries predicted by the model for two cases: $\lambda=1.2$ and $\lambda=0.8$. A value of $\lambda>1$ slightly amplifies the differences predicted by the model relative to the benchmark case, for the key variables. The reason is that a given set of transportation infrastructure differences in the data, translate into more than proportional differences in 
transport sector TFP in the model. The opposite results are obtained for a value of $\lambda$ lower than the benchmark.

Preference for agriculture The benchmark model was calibrated to a long-run share of labor in agriculture of $0.5 \%$, implying $\phi=0.005$. Other papers, like Gollin, Parente and Rogerson (2004) assume that in the long-run the agricultural sector disappears, which implies a long-run share of labor in agriculture of zero. In the second row of Table 5, I report the disparity predicted by the model when $\phi=0$. Relative to the benchmark, the case with $\phi=0$ improves the performance of the model. The reason is that with this value for $\phi$, consumers will devote all their income to the nonagricultural good once they have met their subsistence needs for food. For given productivity gains, induced by transportation improvements, the share of labor is more responsive, and thus the sectoral re-allocation effect implied by the model larger.

Land elasticity in agriculture In the benchmark calibration I set the value of $\alpha$ equal to 0.7 , which implies a land elasticity of 0.3 . This value is within the ballpark of estimates of agricultural production functions, 0.1-0.4 (see for example Hayami and Ruttan, 1985). In Table 5, I report the results for the case in which $\alpha=0.6$, corresponding to a land elasticity of 0.4. The disparities in agricultural and aggregate productivity predicted by the model increase in this case. Intuitively, a higher $1-\alpha$ implies that diminishing returns to labor are more intense. Therefore, for a given transportation TFP, the labor that the unproductive region of a poor country has to devote to agriculture is higher. This reduces average agricultural and therefore aggregate productivity for poor economies more relative to richer ones.

Land elasticity in non-agriculture The land elasticity for non-agriculture used in the original calibration, 0.06, was taken from Caselli and Coleman (2001), as reported by the Bureau of Labor Statistics. In Table 5, I report results for a land elasticity in non-agriculture of 0.2 (i.e., $\sigma=0.8$ ). This value implies that the diminishing returns to labor in non-agriculture are more intense. For a given transport TFP, a higher share of labor is required in nonagriculture to produce the same amount of non-agricultural goods. Increasing the share of labor in non-agriculture reduces non-agricultural productivity. The problem is more severe for rich countries that have most of their labor force in non-agriculture. Thus the disparity 
in aggregate productivity predicted by the model falls. The differential in agricultural productivity falls because the decline in non-agricultural productivity raises the producer cost of intermediate inputs more in rich countries.

Iceberg transport costs In the benchmark calibration the values of $\varphi_{a}$ and $\varphi_{m}$ were normalized to one, i.e., I assumed there were no iceberg costs. A value of less than one for either $\varphi_{a}$ or $\varphi_{m}$ implies that some of the goods shipped from one region never make it to the destination region. A decline in $A_{t}$ affects the transportation sectors of both regions symmetrically. A value of $\varphi_{a}\left(\varphi_{m}\right)$ less than one will reduce the transporting capability of the West (East) only, which exports the agricultural (non-agricultural) good. In Table 5 , I consider a value of 0.9 for each of $\left(\varphi_{a}, \varphi_{m}\right)$ alternatively. A higher iceberg cost in the agricultural exporting region (lower $\varphi_{a}$ ) will have a similar effect as a lower $A_{t}$, on agricultural and aggregate productivity but will not affect the manufacturing sector. In this case the disparity in productivities predicted by the model is higher than in the benchmark. A higher iceberg cost in the non-agricultural producing region will also increase the predicted disparity between rich and poor countries but this will come through the non-agricultural sectors without affecting the disparity in agricultural productivity.

Land to population ratios One of the dimensions across which countries differ in the benchmark experiment is the aggregate land to population ratios. In the next to last row of Table 5, I report the results for the experiment in which countries differ only with respect to economy-wide productivity and transportation TFP, but are identical with respect to the land to population ratios (assumed equal to the US values). The labor productivity predicted by the model falls. The difference between these results and the benchmark ones identify the contribution of differences in arable land to population ratios in accounting for differences in productivity across nations. ${ }^{24}$ The reason that the predicted disparity falls, is that in the data poor countries have lower land to population ratios than rich countries (the factor difference between the $5 \%$ rich and poor is 3.6). In the model a lower land to population ratio translates to a lower labor productivity in agriculture, thereby inducing a lower aggregate productivity.

\footnotetext{
${ }^{24}$ Note however that these results are not comparable to the results for the two-sector model reported in Table 2 because in that experiment countries differed with respect to their land to population ratios.
} 
Removing this channel reduces the predicted gap.

Role of intermediate inputs In the benchmark model, intermediate goods are traded across regions, just as final commodities. A low transport TFP has two effects, (i) it prevents regions from specializing in the goods in which they possess a comparative advantage, (ii) it reduces farmers' access (in the West) to the non-agricultural intermediate inputs. Both these channels reduce average agricultural productivity in the economy. In the last row of Table 5, I consider the counterfactual, in which the second channel is not present. As is clear the productivity disparities, between the richest and poorest nations, predicted by the model without intermediate inputs are much smaller. Intuitively, the additional source of distortion - channel (ii), hits the poorest countries the hardest because they are close to subsistence. Removing that distortion, the only source of variation across countries is channel (i). The results indicate that both sources of distortion are important for understanding the current situation of poor nations.

\section{Concluding Remarks}

This paper makes the point that high transport costs, induced by poor infrastructure, can reduce aggregate labor productivity by distorting the allocation of aggregate resources within and between the agricultural and the non-agricultural sectors. Proxying differences in transportation TFP with differences in transportation infrastructure stocks observed in the data, the paper quantifies the role of transportation for understanding cross-country income differences, in the context of a simple three-sector general equilibrium model.

The quantitative results indicate that the response of aggregate productivity to transportation improvements is asymmetric for developed and developing countries: the potential productivity gains from establishing a more efficient transportation network are orders of magnitude higher for poor countries.

I chose to illustrate the results using a simple model, in order to make the key economic forces transparent. There are features left out of the model, which could potentially have substantial further implications for cross-country income differences. First, I have treated each country as being a closed economy. In this model the only unexploited gains that high 
transport costs impart, are the ones from inter-regional trade within countries. One would expect that between country productivity differences are much more pronounced than within country differences, and thus the unexploited opportunities from missed trade much larger. International transport costs have fallen dramatically over the past century and are not likely to pose a significant barrier to trade. The within country transport costs however, can have significant international trade effects: low transportation infrastructure increases the cost of delivering goods to highly populated interior regions in developing countries, rendering such trades unprofitable.

Second, I have worked with a static model. There could be additional insights from moving to a dynamic model. Recent research (for example, Gollin, Parente and Rogerson, 2004) suggests that improvements in agricultural productivity may speed up the turning point to modern growth. From this paper then one could imagine that improvements in transportation TFP, through their effect on agricultural productivity, can affect the timing and the process of the structural transformation. This would be in line with Rostow's (1956) thesis that transportation innovations, such as the railroad, are significant contributors to "take-offs".

The paper has a number of policy implications and recommendations. First, even if trade liberalization reduces policy barriers, the effective rate of protection offered by transport costs remains high for developing countries. My analysis suggests that to raise agricultural and aggregate productivity in poor countries, it is important to encourage the improvement of transportation networks. Reductions in transport costs in developing countries will allow the reallocation of resources towards the more productive units within sectors and will permit the more intense use of modern intermediate inputs by the agricultural producing regions. This will raise agricultural productivity and will free resources to the non-agricultural sector. Further, the analysis has a key implication for the design of policy by international organizations (such as the World Bank) regarding the allocation of funds: the poorest countries are the ones that will experience the largest productivity gains from improvements in their transportation networks. 


\section{A Data Description}

Penn World Tables, v5.6 Summers and Heston (1991) use data collected under the World Bank's, International Comparisons Project (ICP). The ICP data are based on final sales prices, which include trade and marketing margins, as well as taxes. Summers and Heston (1991) have used the information provided by the ICP to construct comparable measures of real GDP and its components as well as comparable price indices. A detailed description of the aggregation methodology is provided in Summers and Heston (1991). The variables I use from the PWT are: real GDP per worker, real GDP per capita, population, PPP for aggregate GDP.

Food and Agricultural Organization (FAO) of the United Nations Rao (1993) uses data from the FAO production accounts to construct comparable measures of agricultural output, as well as comparable agricultural price indices for a set of 103 countries. The agricultural output statistics are computed using a methodology similar to that used in computing the PWT statistics. The main difference is that the FAO statistics are based on prices paid/received by farmers at the farm gate. A description of the data and the methodology is contained in Rao (1993). The variables I use from the FAO are: economically active population engaged in agriculture, total arable land, agricultural GDP, agricultural final output, agricultural PPP for final output, non-agricultural intermediate input expenditures, PPP for non-agricultural intermediate input expenditures.

Canning's Infrastructure Data Canning (1998) has constructed a database of physical infrastructure stocks for a cross-section of 152 countries over 1950-95. The database contains the following infrastructure measures: kilometers of roads, kilometers of paved roads, kilometers of railway lines, number of telephones, number of telephone main lines, KW of electricity generating capacity. I use the transportation infrastructure data for 1985 from this database. For most variables, Canning reports both the raw data (as they appear in the original sources) and the processed data (in which he has linked and interpolated series). I use the processed data for paved roads and railways (as recommended), and the raw data for total roads (no processed data available).

State Level Data - United States The U.S. state-level data on indices of labor inputs, land inputs, intermediate inputs and outputs are obtained from Ball, Butault and Nehring (2001) of the U.S. Department of Agriculture. Output is defined as, gross output leaving the farm, and is calculated at factor cost. Intermediate inputs include inputs both from within and outside the farm sector. Land corresponds to total land in farms as reported by the Census of Agriculture. The labor input is hours worked in agriculture. Using the above data I calculate indices of relative agricultural productivity and relative intermediate input 
intensity between the West and the East. The 1985 state level data on farm acreage, total employment, agricultural, non-agricultural and transportation employment are obtained from the 1987 Statistical Abstract of the United States (U.S. Census Bureau). Real total gross state output and output of the agricultural, non-agricultural, and transportation sectors, by state, are obtained from the Bureau of Economic Analysis (Regional Economic Accounts, U.S. Department of Commerce), for 1985.

State Level Data - India Berk Özler, Gaurav Datt, and Martin Ravallion (1996) have created a Database on Poverty and Growth in India, for the World Bank. From this database, which contains detailed country level and state level Indian data, I use 1991 data on the following variables: agricultural SDP (state domestic product) at current prices, hectares of net sown area, total population, and rural population. To calculate employment in agriculture for each state I also use data on the proportion of the rural population that are self-employed in agriculture, for each state, from Sumir Meghani (2003), A State-Level Examination of Rural Poverty in India from 1983-1994, Stanford, Mimeo.

Tables Table A.1 contains summary statistics for the following variables: aggregate GDP per worker $\left(\frac{G D P}{n}\right)$, agricultural final output per worker $\left(\frac{F O_{a}}{n_{a}}\right)$, agricultural GDP per worker $\left(\frac{G D P_{a}}{n_{a}}\right)$, non-agricultural GDP per worker $\left(\frac{G D P_{m}}{n_{m}}\right)$, share of non-agricultural intermediate inputs used in agricultural final output $\left(\frac{i n p u t s}{F O_{a}}\right)$, share of labor employed in agriculture $\left(\frac{n_{a}}{n}\right)$, and the transportation infrastructure index $(T I I)$. Countries are ranked according to their level of aggregate real GDP per worker. For each variable, I report the average of the richest $5 \%$, the poorest $5 \%$, and their ratio.

Table A.1: Summary Statistics

\begin{tabular}{lccccccc}
\hline & $\frac{G D P}{n}$ & $\frac{F O_{a}}{n_{a}}$ & $\frac{G D P_{a}}{n_{a}}$ & $\frac{G D P_{m}}{n_{m}}$ & $\frac{\text { inputs }}{F O_{a}}$ & $\frac{n_{a}}{n}$ & $T I I$ \\
\hline Rich 5\% & $30,497.4$ & $19,644.7$ & $12,236.6$ & $31,468.7$ & 0.4 & 0.049 & 4.512 \\
Poor 5\% & 940.8 & 196.8 & 172.9 & $8,072.6$ & 0.1 & 0.884 & 0.158 \\
Ratio & 32.4 & 99.8 & 70.8 & 3.9 & 3.2 & 0.056 & 28.5 \\
\hline
\end{tabular}

Table A.2 includes pair-wise correlations between the transportation infrastructure index and key variables of interest.

Table A.2: Correlations with TII

\begin{tabular}{lc}
\hline Variables & correlation with transport index \\
\hline aggregate productivity & 0.73 \\
agricultural productivity & 0.80 \\
non-agricultural productivity & 0.56 \\
agr. employment share & -0.61 \\
share of interm. inputs in agr. output & 0.57 \\
relative price of intermediate inputs & -0.35 \\
\hline
\end{tabular}


In Table A.3, I report agricultural labor productivity for each one of the 14 main Indian states, as well as the share of each state's output in total agricultural output (where total agricultural output is the sum of the outputs of these states). Productivities are reported relative to Uttar Pradesh.

Table A.3: State Level Data, India, 1991

\begin{tabular}{lcc}
\hline State & Agric. Labor Productivity & Share of Agric. Production \\
\hline Andhra Pradesh & 2.41 & 0.09 \\
Assam & 1.15 & 0.03 \\
Bihar & 0.99 & 0.08 \\
Gujarat & 2.18 & 0.05 \\
Panjab and Harayana & 3.97 & 0.11 \\
Karnataka & 1.75 & 0.06 \\
Kerala & 2.10 & 0.03 \\
Madhya Pradesh & 1.21 & 0.08 \\
Maharashtra & 2.16 & 0.09 \\
Orissa & 0.97 & 0.03 \\
Rajasthan & 1.32 & 0.07 \\
Tamil Nadu & 2.04 & 0.04 \\
Uttar Pradesh & 1.00 & 0.17 \\
West Bengal & 1.92 & 0.07 \\
\hline
\end{tabular}

\section{B Mathematical Appendix}

Proof of Proposition $1\left(\frac{n_{a j}}{n_{j}}\right)^{a u t}$. is the solution to $\frac{n_{a j}}{n_{j}}$ in the following equation,

$$
\begin{aligned}
\frac{n_{a j}}{n_{j}}= & \frac{\sigma(1-\phi) \bar{a}}{\sigma-\beta \phi(\sigma-\alpha)} \cdot \frac{\left(\frac{n_{a j}}{n_{j}}\right)^{\beta(1-\alpha)}\left(1-\frac{n_{a j}}{n_{j}}\right)^{(1-\beta)(1-\sigma)}}{\left(A \varepsilon_{a j}\right)^{\alpha \beta}\left(\frac{L_{a j}}{n_{j}}\right)^{\beta(1-\alpha)}\left(A \varepsilon_{m j}\right)^{1-\beta}\left(\frac{L_{a j}}{n_{j}}\right)^{(1-\beta)(1-\sigma)}\left[\frac{\sigma(1-\beta)}{\alpha \beta}\right]^{1-\beta}} \\
& +\frac{\alpha \beta \phi}{\sigma-\beta \phi(\sigma-\alpha)}
\end{aligned}
$$

Given the solution for the labor share the relative price of manufacturing in the autarkic equilibrium is, $p_{m j}=\frac{\alpha \beta\left(Y_{a j} / n_{a j}\right)}{\sigma\left(Y_{m j} / n_{m j}\right)}$. The results in the proposition follow from the requirement that, $p_{m E}^{a u t}<p_{m W}^{a u t}$. The case without subsistence is derived when $\bar{a}=0$ in the above equation.

Solution of Equilibrium for Simple Case In the simple case with one factor of production, described in section 3.5, equilibrium prices can be solved for with knowledge of the production technologies alone. The price of agriculture in the West (the numeraire) is normalized to unity, which implies that the wage rate in the West is $w_{W}=A \varepsilon_{a W}$. Wage equalization across agriculture and transportation in the West imply that the relative price of transportation is $p_{t W}=\frac{A \varepsilon_{a W}}{A_{t}}$. From the first order condition of the exporter in the West 
it follows that the price of an agricultural good arriving in the East from the West will be $p_{a E}=\frac{1}{\varphi_{a}}\left[1+\frac{A \varepsilon_{a W}}{A_{t}}\right]$. Given that the relative price of imported agricultural goods in the East must be the same as that of the locally produced ones (by arbitrage), the wage rate in the East is $w_{E}=p_{a E} A \varepsilon_{a E}$. Free mobility of labor across agriculture and manufacturing in the East imply a relative price of manufacturing in the East of $p_{m E}=p_{a E} \frac{\varepsilon_{a E}}{\varepsilon_{m E}}$. Free mobility of labor across manufacturing and transportation, gives the relative freight cost in the East, $p_{t E}=p_{m E} \frac{A \varepsilon_{m E}}{A_{t}}$. From the exporter's pricing function in the East, the price of manufactured goods arriving in the West is $p_{m W}=\frac{1}{\varphi_{m}}\left[1+\frac{A \varepsilon_{m E}}{A_{t}}\right] p_{m E}$.

Given relative prices, the labor allocations across sectors, can be solved for in each region. Using the market clearing conditions in the West, the share of labor employed in agriculture in that region is,

$$
\frac{n_{a W}}{n_{W}}=\frac{A_{t}+\bar{a}}{A \varepsilon_{a W}+A_{t}}
$$

From the agricultural market clearing condition in the East and $\frac{M_{a E}}{\varphi_{a}}$, the share of labor devoted to agriculture in the East is,

$$
\frac{n_{a E}}{n_{E}}=\frac{\bar{a}\left(1+\varphi_{a} \frac{n_{W}}{n_{E}}\right)-\varphi_{a} \frac{n_{W}}{n_{E}} A \varepsilon_{a W} \frac{n_{a W}}{n_{W}}}{A \varepsilon_{a E}}
$$

From the market clearing conditions for manufacturing and transportation in the East, we can solve for the share of labor in manufacturing in the East,

$$
\frac{n_{m E}}{n_{E}}=\frac{A_{t}\left(1-\frac{n_{a E}}{n_{E}}\right)+\bar{a} \frac{p_{a E}}{p_{m E}}}{A \varepsilon_{m E}+A_{t}}
$$

As is clear from (34) and (35) a higher transportation TFP will lead to a re-allocation of farming activity from the East to the West.

Proof of Proposition 3 The condition for the West to be completely specialized in farming is that the West cannot produce the manufacturing good at a lower price than it can import it, $p_{m W}^{t r}<p_{m W}^{a u t}$. The autarky relative price of the manufactured good in the West is independent of the TFP in transportation, $p_{m W}^{a u t .}=\frac{\varepsilon_{a W}}{\varepsilon_{m E}}$. However, $p_{m W}^{t r}=\frac{1}{\varphi_{m}}\left(1+\frac{A \varepsilon_{m E}}{A_{t}}\right) p_{m E}^{t r .}$ depends negatively on $A_{t}$. Using the relative prices from B.2, the difference $p_{m W}^{t r}-p_{m W}^{a u t}$ can be re-written as a function of $A_{t}$,

$$
f\left(A_{t}\right)=\frac{1}{\varphi_{a}} \cdot \frac{1}{\varphi_{m}} \cdot \frac{\varepsilon_{a E}}{\varepsilon_{m E}} \cdot \frac{\varepsilon_{m W}}{\varepsilon_{a W}}\left[1+\frac{A \varepsilon_{m E}}{A_{t}}\right]\left[1+\frac{A \varepsilon_{a W}}{A_{t}}\right]-1
$$

The function $f(\cdot)$ is strictly decreasing in $A_{t}$. This together with $\lim _{A_{t} \rightarrow 0^{+}} f\left(A_{t}\right)=\infty$ and $\lim _{A_{t} \rightarrow \infty} f\left(A_{t}\right)=\frac{1}{\varphi_{a}} \frac{1}{\varphi_{m}} \frac{\varepsilon_{a E}}{\varepsilon_{m E}} \frac{\varepsilon_{m W}}{\varepsilon_{a W}}-1$ implies that, there exists some level of transportation TFP, $\bar{A}_{t}>0$ that satisfies $f\left(\bar{A}_{t}\right)=0$. That is, $\bar{A}_{t}$ is the value of $A_{t}$ that makes the West indifferent 
between trading and not: $p_{m W}^{t r}=p_{m W}^{a u t}$. For all $A_{t}<\overline{A_{t}}$ it is not profitable for the West to trade.

\section{References}

[1] Ahmed, R., and Hossain, M., (1990), "Developmental Impact of Rural Infrastructure in Bangladesh", IFPRI, Research Report 83, Washington DC.

[2] Antle, John, (1983), "Infrastructure and Aggregate Agricultural Productivity: International Evidence", Economic Development and Cultural Change, Vol. 31, No. 3, pp.609619.

[3] Atkenson, Andrew and Masao Ogaki (1996), "Wealth-varying Intertemporal Elasticities of Substitution: Evidence from Panel and Aggreate Data ", Journal of Monetary Economics, 38, pp. 507-534.

[4] Ball, V. Eldon, Jean-Pierre Butault, and Richard Nehring (2001), "US Agriculture, 1960-96, A Multilateral Comparsion of Total Factor Productivity", Technical Bulletin 1895, Economic Research Service, USDA.

[5] Binswanger, H.P., Khandker, S.R., Rosenzweig, M.R. (1993), "How infrastructure and financial institutions affect agricultural output and investment in India", Journal of Development Economics, Vol.41, pp. 337-366.

[6] Canning, David (1998), "A Database of World Stocks of Infrastructure, 1950-95”, World Bank Economic Review, Vol.12, No.3.

[7] Caselli, Francesco and Wilbur John Coleman II (2001), "The US Structural Transformation and Regional Convergence: A Reinterpretation", Journal of Political Economy, Vol. 109, No.3, pp.584-616.

[8] Caselli, Francesco (2004), "Accounting for Cross-Country Income Differences", Manuscript, Harvard University.

[9] Chari, V.V., Patrick J. Kehoe and Ellen R. McGrattan (1996), "The Poverty of Nations: A Quantitative Investigation", Federal Reserve Bank of Minneapolis, Research Department Staff Report 204/JV.

[10] Chenery, Hollis B., and Moshe Syrquin (1975), Patterns of Development, 1950-1970, London: Oxford University Press.

[11] Cordoba, Juan Carlos and Marla Ripoll (2005), "Agriculture, Aggregation, and CrossCountry Income Differences", Manuscript. University of Pittsburgh. 
[12] Craig, Barbara J., Philip G. Pardey, and Johannes Roseboom (1997), "International Productivity Patterns: Accounting for Input Quality, Infrastructure and Research", American Journal of Agricultural Economics, 79, pp. 1064-1076.

[13] Easterly, William, and Sergio Rebelo (1993), "Fiscal Policy and Economic Growth: An Empirical Investigation", Journal of Monetary Economics, 32, pp. 417-458.

[14] Echevarria, Christina (1997), "Changes in Sectoral Composition Associated with Economic Growth", International Economic Review, Vol.38, Issue 2, pp.431-452.

[15] Fei, John C.H., and Gustav Ranis (1964), Development of the Labor Surplus Economy: Theory and Policy, Economic Growth Center, Yale University, Homewood, Illinois.

[16] Fishlow, Albert (1965), American Railroads and the Transformation of the Ante-bellum Economy, Harvard University Press.

[17] Fishlow, Albert (2000), "Internal Transportation in the Nineteenth and Early Twentieth Centuries", in The Cambridge Economic History of the United States, Volume II, (eds.) Stanley Engerman and Robert Gallman, Cambridge University Press.

[18] Fogel, Robert (1964), Railroads and American Economic Growth: Essays in Econometric History, John Hopkins Press, 1964.

[19] Glaeser, Edward L., and Janet E. Kohlhase (2003), "Cities, Regions, and the Decline of Transport Costs, NBER, Working Paper 9886.

[20] Gollin, Douglas, Stephen L. Parente, and Richard Rogerson (2002), "The Role of Agriculture in Development", American Economic Review: Papers and Proceedings.

[21] Gollin, Douglas, Stephen L. Parente, and Richard Rogerson (2004), "The Food Problem and the Evolution of International Income Levels", Manuscript.

[22] Hall, Robert E. and Charles I. Jones (1999), "Why Do Some Countries Produce so much more Output per Worker than Others?", Quarterly Journal of Economics, Vol.114, No.1, pp.83-116.

[23] Hansen, Gary D. and Edward C. Prescott (2002), "Malthus to Solow", American Economic Review, 92(4), pp.1205-1217.

[24] Hayami, Yujiro and Vernon W. Ruttan (1985), Agricultural Development: An International Perspective, Baltimore: Johns Hopkins University Press.

[25] Holmes, Thomas J., and James A. Schmitz Jr. (2001), "Competition At Work: Railroads vs. Monopoly In The US Shipping Industry", Federal Reserve Bank of Minneapolis Quarterly Review, Vol.25, No.2, pp. 3-29. 
[26] Klenow, Peter J. and Andres Rodriquez-Clare, "The Neoclassical Revival in Growth Economics: Has it Gone Too Far?", in Ben S. Bernanke and Julio J. Rotemberg, eds. NBER Macroeconomics Annual 1997, Cambridge, MA: MIT Press

[27] Kongsamut, Piyahaba, Sergio Rebelo, and Danyang Xie (2001), "Beyond Balanced Growth", Review of Economic Studies, 68, pp. 869-882.

[28] Kuznets, Simon (1966), Modern Economic Growth, London, George Allen \& Unwin Ltd.

[29] Limao and Venables (2001), "Infrastructure, Geography, Disadvantage, Transport Costs and Trade", World Bank Economic Review, Vol.15, Issue 3, pp. 41-70.

[30] Lucas, Robert E. (2000), "Some Macroeconomics For the 21st Century", Journal of Economic Perspectives, Vol.14, No.1, pp. 159-168.

[31] Mankiw, N. Gregory, David Romer, and David N. Weil (1992), "A Contribution to the Empirics of Economic Growth", Quarterly Journal of Economics, 107, pp. 407-438.

[32] McGrattan, Ellen R. and James A. Schmitz, Jr. (1998), "Explaining Cross Country Income Differences", Federal Reserve Bank of Minneapolis, Research Department Staff Report 250 .

[33] Minten, Bart, and Steven Kyle (1999), "The Effect of Distance and Road Quality on Food Collection, Marketing margins, and Traders' Wages: Evidence From the Former Zaire", Journal of Development Economics, Vol. 60, pp. 467-495.

[34] Ngai, Rachel L. and Christopher Pissarides (2005), "Structural Change in a MultiSector Model of Growth", CEPR Discussion Paper 4763.

[35] North, Douglass (1958), "Ocean Freight Rates and Economic Development: 1750-1913", Journal of Economic History, 18(4), pp. 537-555.

[36] Parente, Stephen L., and Edward C. Prescott (2000), Barriers To Riches, MIT Press, Cambridge, Massachusetts.

[37] Prescott, Edward C. (1998), "Needed: A Theory of Total Factor Productivity", International Economic Review, 39, pp. 525-549.

[38] Rao, Prasada D.S. (1993), Intercountry Comparisons of Agricultural Output and Productivity, FAO Economic and Social Development Paper, Food and Agriculture Organization of the United Nations.

[39] Restuccia, Diego and Richard Rogerson (2003), "Policy Distortions and Aggregate Productivity with Heterogeneous Plants", Mimeo, University of Toronto. 
[40] Restuccia, Diego, Dennis Tao Yang, and Xiaodong Zhu (2004), "Agriculture and Aggregate Productivity: A Quantitative Cross-Country Analysis", Mimeo, University of Toronto.

[41] Rosenzweig, Mark and Kenneth Wolpin. (1993), "Credit Market Constraints, Consumption Smoothing, and the Accumulation of Durable Production Assets in Low-Income Countries: Investments in Bullocks in India", Journal of Political Economy, 101, pp. 223-244.

[42] Rostow, Walt W. (1956), "The Take-Off Into Self-Sustained Growth", Economic Journal, Vol.66, No.261, pp. 25-48.

[43] Schmitz, James A., Jr. (2003), "Nineteenth Century U.S. Economic Growth: How Important Was the Transportation Revolution?", Manuscript, Federal Reserve Bank of Minneapolis.

[44] Schultz, Theodore W. (1953), The Economic Organization of Agriculture, New York: McGraw Hill.

[45] Summers, Robert, and Alan Heston (1991), "The Penn World Table (Mark 5): An Expanded Set of International Comparisons, 1950-1988", Quarterly Journal of Economics, Vol. 106, Issue 2, pp. 327-368.

[46] Taylor, George Rogers (1964), The Transportation Revolution, 1815-1860, (The Economic history of the United States, v. 4), New York, Holt, Rinehart and Winston.

[47] Williamson, Jeffrey (1974), Late Nineteenth Century American Economic Development: A General Equilibrium History, Cambridge University Press. 
Fig. 1: Real GDP per worker

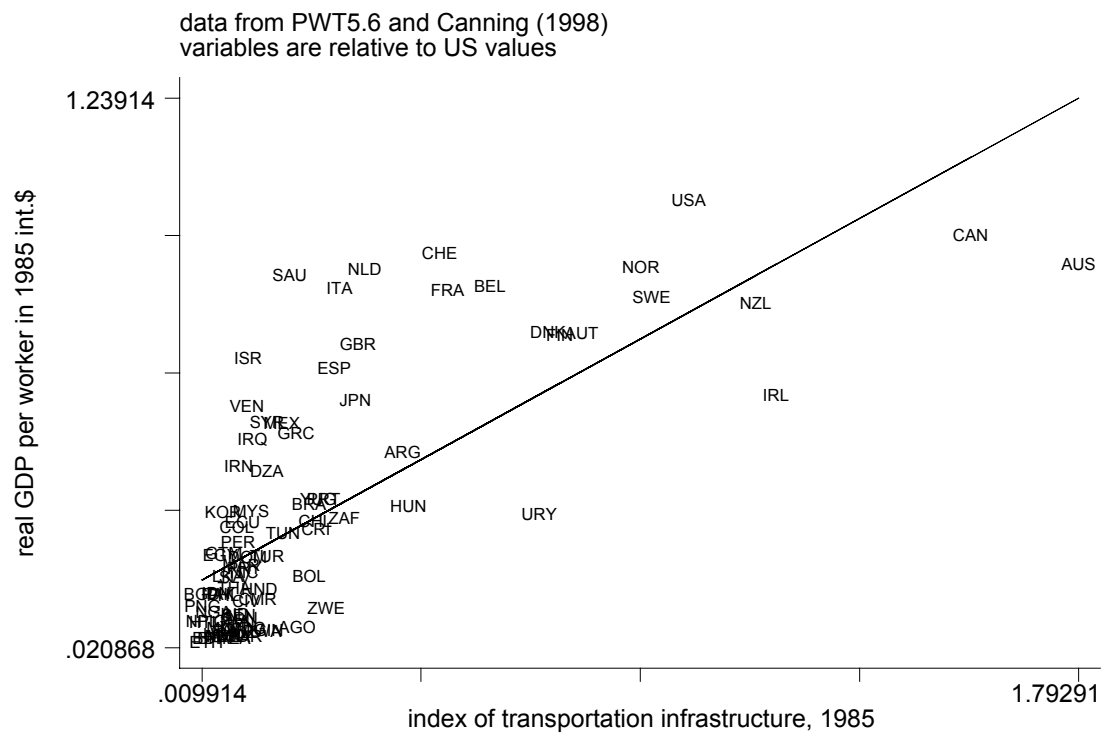

Fig. 2: Real Agricultural GDP per worker

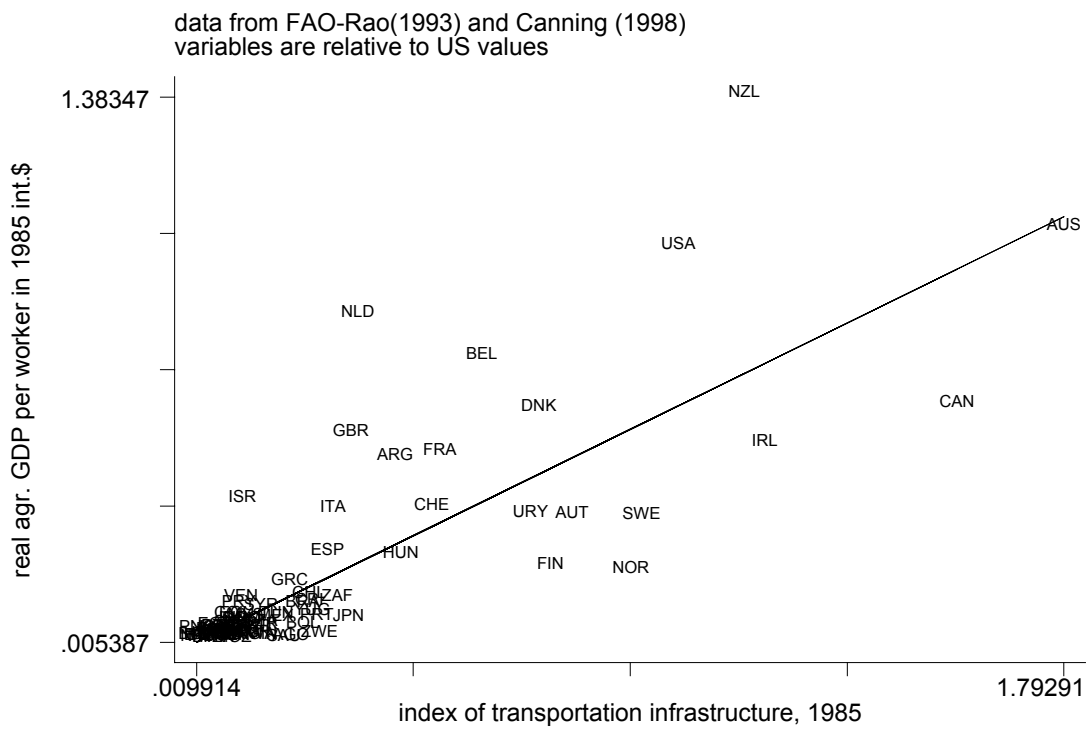

Fig. 3: Real Non-Agricultural GDP per worker

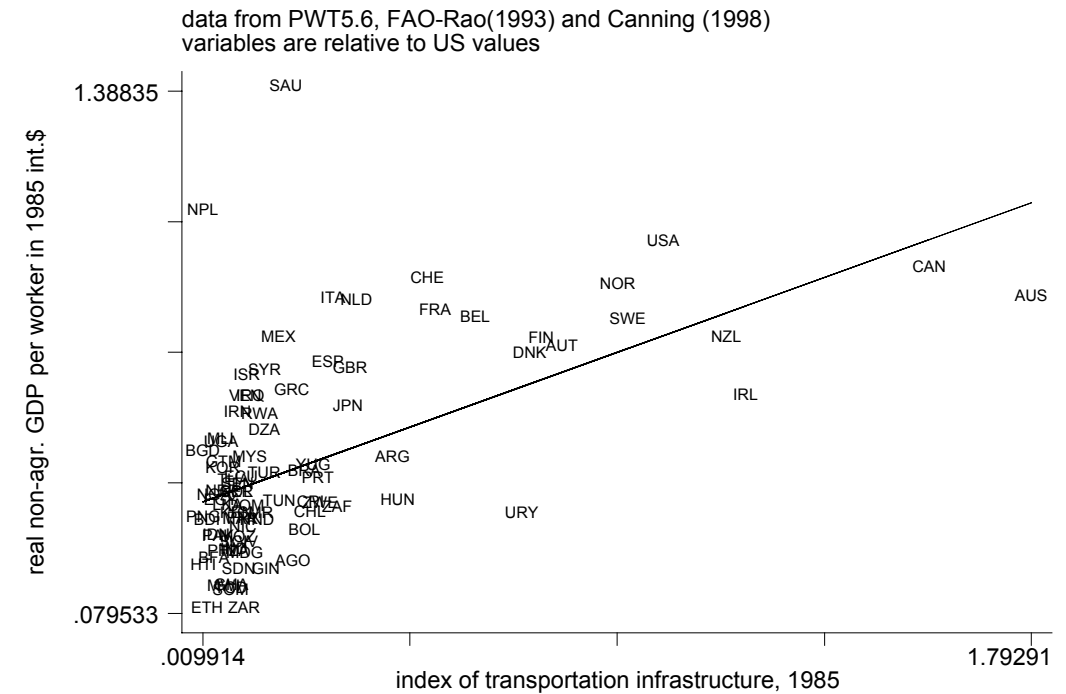


Fig. 4: Share of Labor In Agriculture

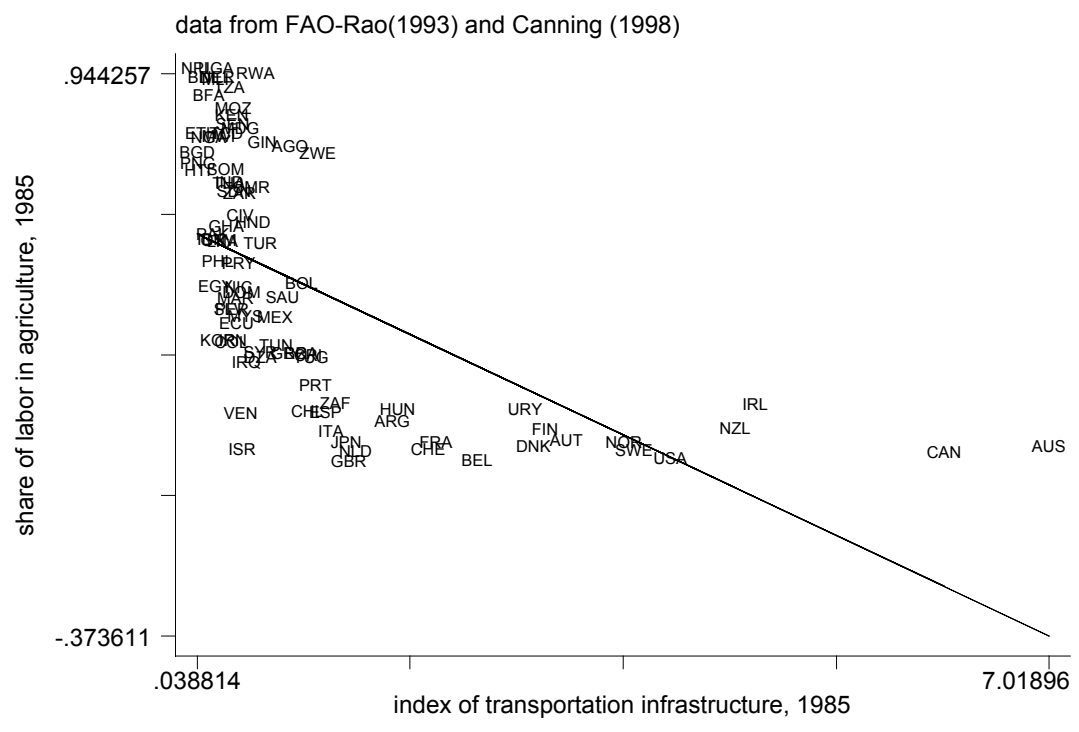

Fig. 5: Relative Price of Intermediate Inputs

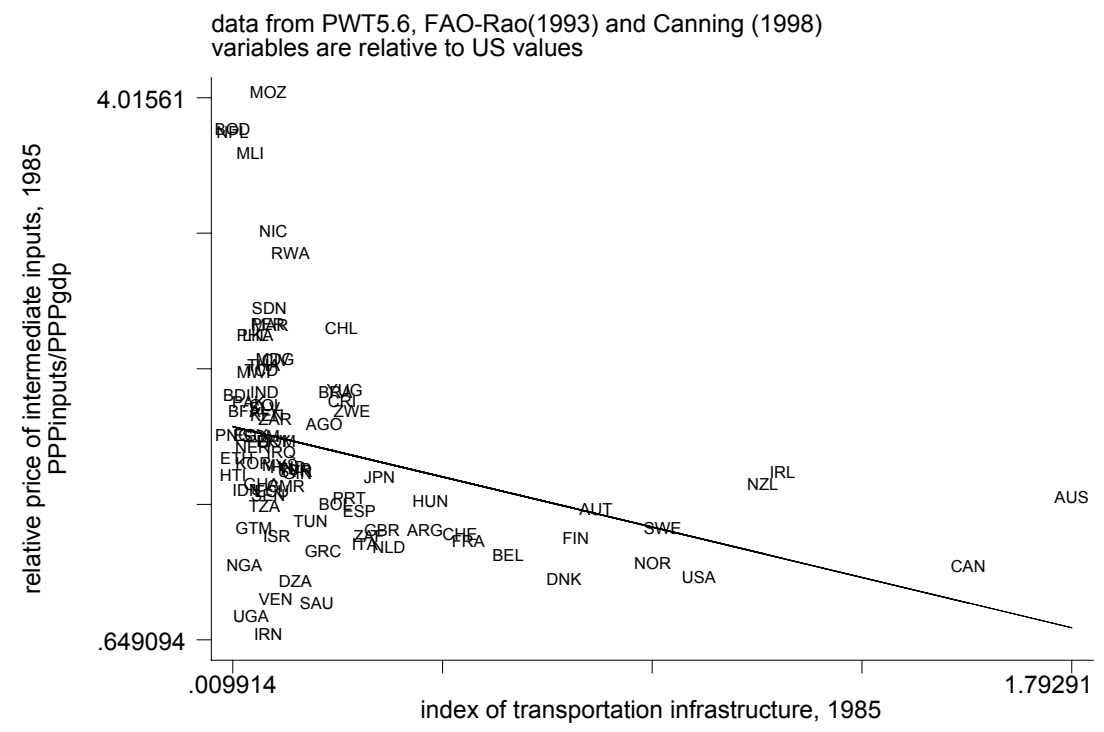

Fig. 6: Share of Intermediate Inputs in Agricultural Output

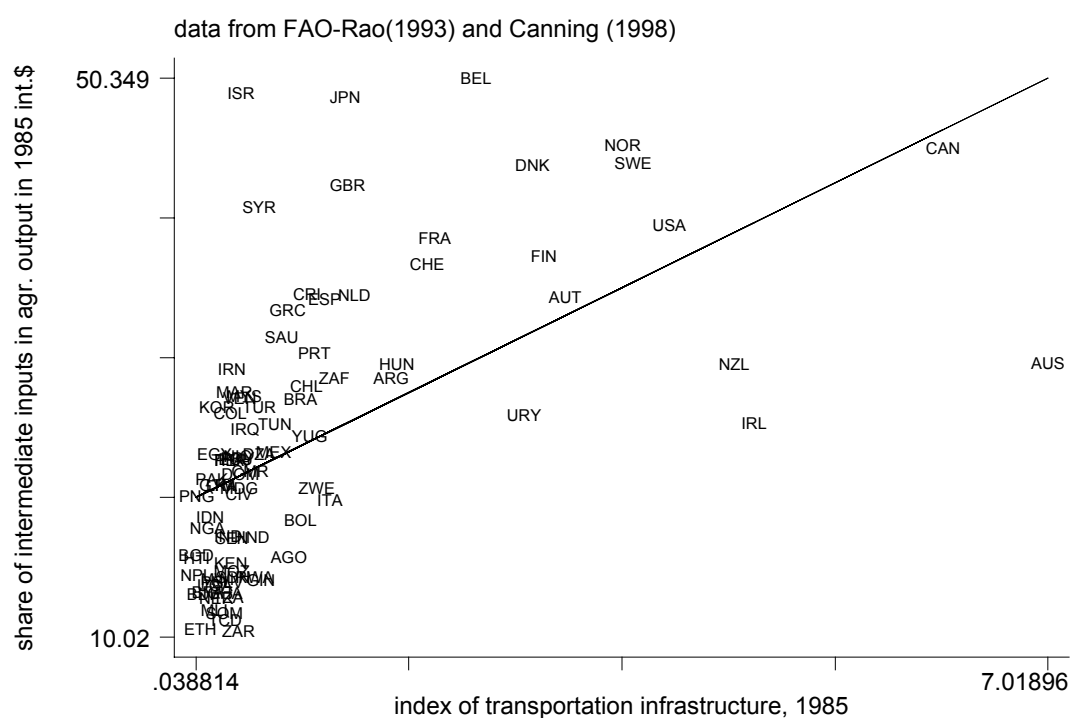


Map 1: Global Map of Land Quality

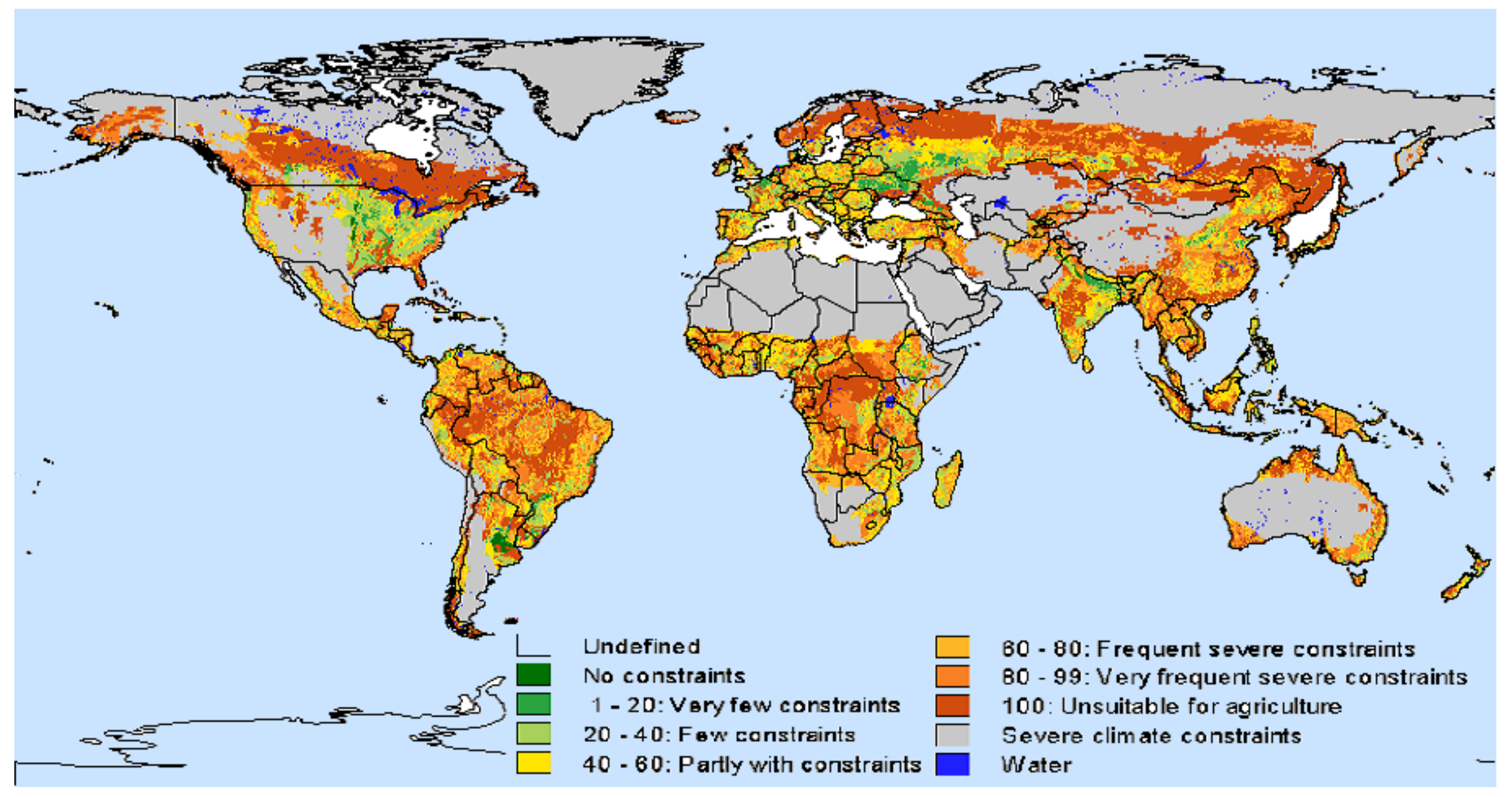

Source: FAO and IIASA 


\section{Map 2: Global Land Cover Characteristics}

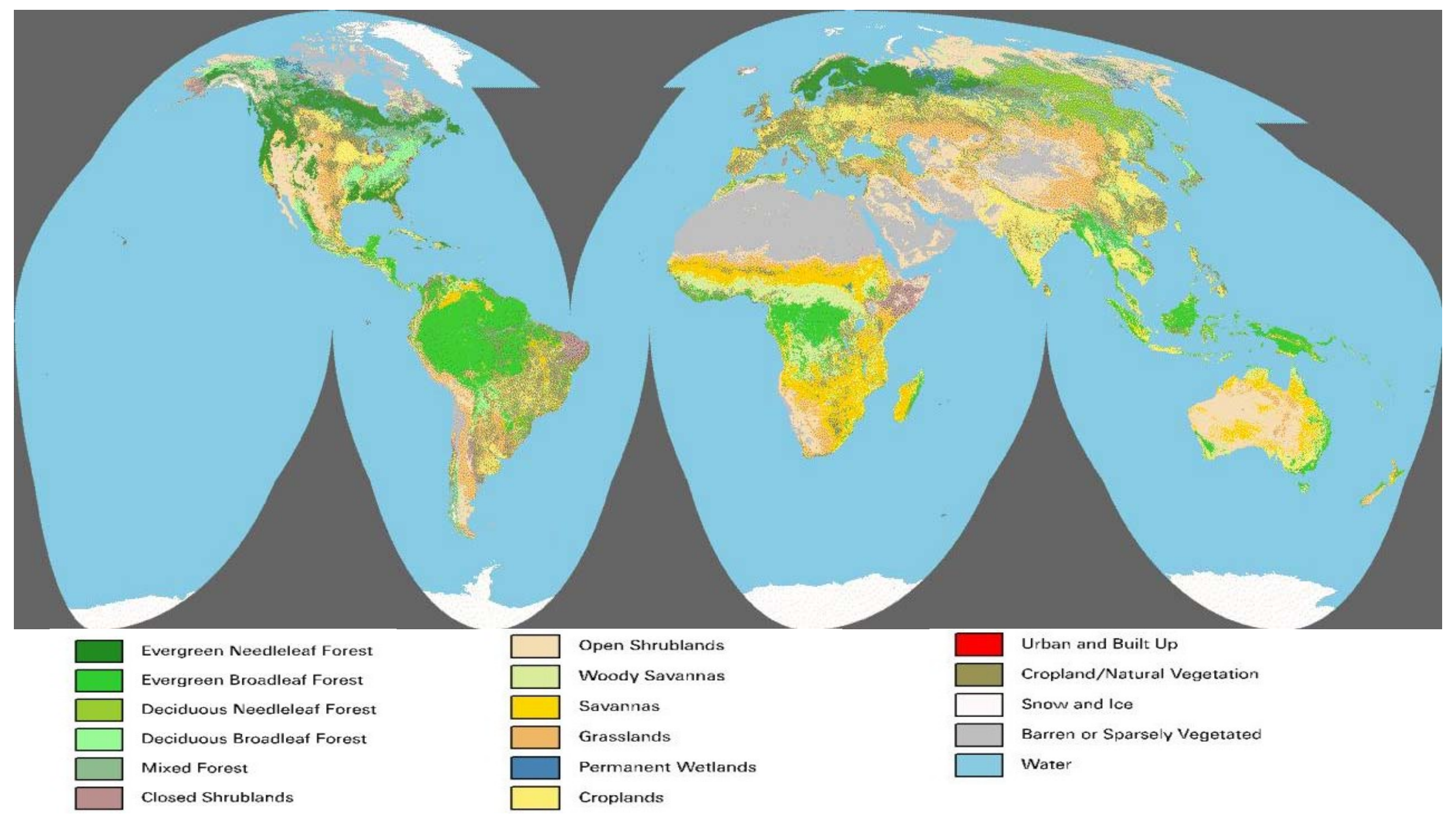

Source: U.S. Geological Survey 